\title{
Self-Organization of Silver-Core Bimetallic Nanoparticles and Their Application for Catalytic Reaction
}

\author{
Kazutaka Hirakawa \\ Faculty of Engineering, Shizuoka University \\ Japan
}

\section{Introduction}

Metal nanoparticles have received much attentions as a building block of advanced materials for nanoscience and nanotechnology (Bönnemann \& Richards, 2001). Their optical, (Fukumi et al., 1994; Lu et al., 1999; Link et al., 1999; Shipway et al., 2000), magnetic (Sun et al., 1999; Teranishi \& Miyake, 1999), and catalytic (Kiely et al., 1998; Pileni, 1998; Bradley, 1994; Harriman, 1990; Lee et al., 1995; Toshima et al., 1995; Bonilla et al., 2000; Siepen et al., 2000) properties have been reported with great interests. The character of metal nanoparticle can be altered by the addition of other metals. Bimetallic nanoparticles, composed of two different metallic elements, have been reported to show outstanding characters different from the corresponding monometallic nanoparticles (Harriman, 1990; Yonezawa \& Toshima, 1993; Toshima \& Hirakawa, 1997, 1999; Toshima \& Wang, 1994; Lee et al., 1995). For example, catalytic activities of gold $(\mathrm{Au})$-core structured bimetallic nanoparticles, gold/platinum (Au/Pt) (Harriman, 1990; Yonezawa \& Toshima, 1993; Toshima \& Hirakawa, 1999), gold/palladium (Au/Pd) (Toshima \& Hirakawa, 1999; Lee et al., 1995), and gold/rhodium (Au/Rh) (Toshima \& Hirakawa, 1999), for hydrogenation and/or water reduction are higher than platinum $(\mathrm{Pt})$, palladium $(\mathrm{Pd})$, and rhodium $(\mathrm{Rh})$ monometallic nanoparticles, respectively. Surprisingly, in some cases, a physical mixture of monometallic nanoparticles such as $\mathrm{Pt}$ and ruthenium $(\mathrm{Ru})$ nanoparticles in solution shows higher catalytic activity than the corresponding monometallic nanoparticles under a certain condition (Toshima et al., 1995; Toshima \& Hirakawa, 1997). This suggests that an interaction between two kinds of monometallic nanoparticles can produce novel nanoparticles. Further, it has been reported that physical mixture of silver (Ag) and other metal nanoparticles, such as $\mathrm{Pt}, \mathrm{Rh}$, and $\mathrm{Pd}$, spontaneously forms the bimetallic nanoparticles with Ag-core structure in aqueous solution. This reaction can be used to construct the core-shell structured novel bimetallic nanoparticles. The formed nanoparticles demonstrate superior character for certain catalytic reactions.

In this chapter, the simple method of the preparation of core-shell structured bimetallic nanoparticles by the physical mixing and the application of the formed novel metal nanoparticles for catalytic reaction are described. The topics of the catalytic reaction presented in this chapter are the visible light induced hydrogen generation (Toshima \& 
Hirakawa, 2003), the removal of reactive oxygen species (Hirakawa \& Sano, 2009), and its application to the chemoprevention of ultraviolet induced biomolecules damage (Hirakwa et al., 2008, 2009).

\section{Spontaneous formation of silver-core bimetallic nanoparticles}

Much attention has been paid to bimetallic nanoparticles, especially those having a core/shell structure (Toshima et al., 2007). From the view point of Au catalysts, bimetallic nanoparticles have received much attention recently. On the other hand, a physical mixture of monometallic nanoparticles such as $\mathrm{Pt}$ and $\mathrm{Ru}$ nanoparticles in solution shows higher catalytic activity than the corresponding monometallic nanoparticles under a certain condition (Toshima et al., 1995; Toshima \& Hirakawa, 1997). Further, it has been reported that physical mixture of $\mathrm{Ag}$ and other metal nanoparticles, such as $\mathrm{Pt}, \mathrm{Rh}$, and $\mathrm{Pd}$, spontaneously forms the bimetallic nanoparticles with Ag-core structure in aqueous solution (Figure 1). In this section, the spontaneous formation of the Ag-core bimetallic nanoparticles is reviewed.

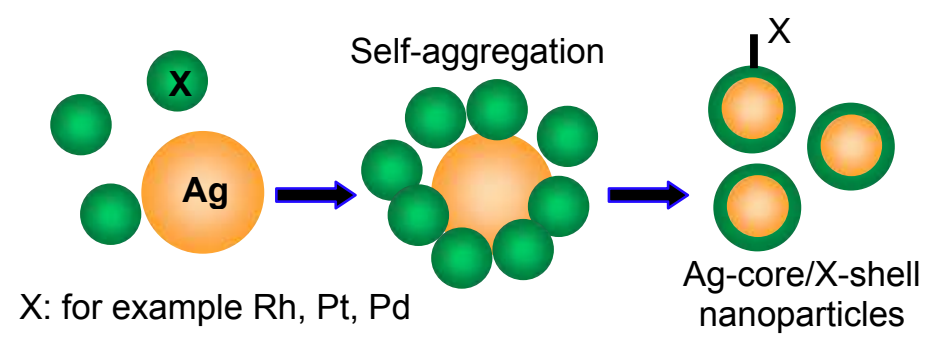

Fig. 1. Schematic diagram of the spontaneous formation of Ag-core bimetallic nanoparticles

\subsection{Siver-core/rhodium-shell bimetallic nanoparticles}

The interaction between Ag and Rh monometallic nanoparticles in solution by physical mixing was reported. The main reason for using Ag and Rh nanoparticles is the reported prominent characteristics of Rh nanoparticles as a catalyst (Toshima \& Hirakawa, 1999), and the expected electronic effect of Ag similar to Au upon enhancement of the catalytic activity of Rh. Furthermore, Ag is inexpensive metal compared with Au. The colloidal dispersions of $\mathrm{Ag}$ and Rh monometallic nanoparticles protected by poly( $N$-vinyl-2-pyrrolidone) (PVP), a water soluble polymer, were prepared by an alcohol reduction method (Hirai et al., 1979). Average diameters of $\mathrm{Ag}$ and $\mathrm{Rh}$ monometallic nanoparticles were $7.5 \mathrm{~nm}$ and $2.2 \mathrm{~nm}$, respectively.

\subsubsection{Surface plasmon absorption of siver-core bimetallic nanoparticles}

Colloidal sol of Ag nanoparticles shows characteristic plasmon absorption aeound $400 \mathrm{~nm}$ (Henglein, 1979). The plasmon absorption band of Ag nanoparticles decreased by addition of Rh nanoparticles and was almost completely extinguished within $30 \mathrm{~min}$ after mixing (Figure 2). The parts of plasmon absorption in larger wavelength region were preferentially 
extinguished within $10 \mathrm{~min}$, suggesting that influences of $\mathrm{Rh}$ nanopartilces on $\mathrm{Ag}$ nanoparticles depend on the size of the Ag nanoparticles. When relatively smaller molar quantity of Rh to Ag was added, the plasmon absorption was not completely extinguished. More than 40 atom-mol\% of $\mathrm{Rh}$ against to $\mathrm{Ag}$ was required to extinguish the plasmon absorption band completely.

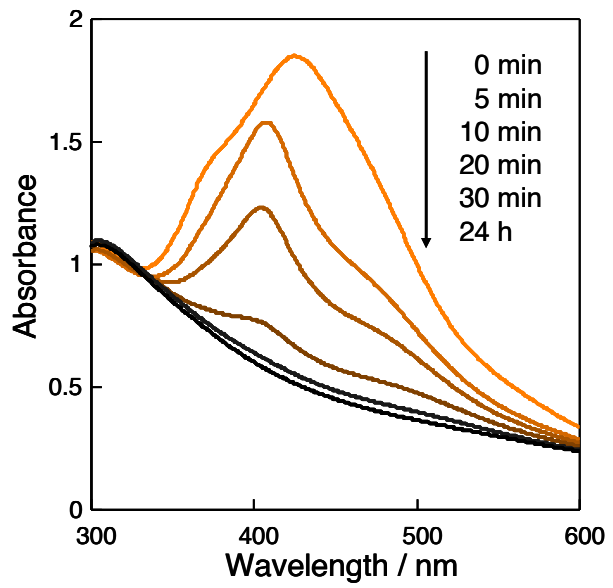

Fig. 2. UV-Vis spectral change of the physical mixtures of dispersions of Ag and Rh nanoparticles. The aqueous solutions of $\mathrm{Ag}(1$ atom-mmol L-1, $50 \mathrm{~mL})$ and $\mathrm{Rh}(1 \mathrm{atom}-\mathrm{mmol}$ $\mathrm{L}^{-1}, 50 \mathrm{~mL}$ ) nanoparticles were mixed.

\subsubsection{Transmission electron microgram of the siver-core bimetallic nanoparticles}

Figure 3 shows transmission electron microscopy (TEM) photographs of the physical mixtures of $\mathrm{Ag}$ and $\mathrm{Rh}$ monometallic nanoparticles. The samples for TEM measurement were prepared by drying the aqueous dispersions of the physical mixtures of $\mathrm{Ag}$ and $\mathrm{Rh}$ nanoparticles under vacuum in 0,10 , and $30 \mathrm{~min}$, and $24 \mathrm{~h}$, respectively, after mixing. Relatively large particles are attributed to Ag nanoparticles, and rather small ones are $\mathrm{Rh}$ nanoparticles. The TEM photographs showed that Rh particles gathered around Ag particle to surround within several minutes, comparable period of the extinction of plasmon absorption. Interestingly, these aggregated particles changed into homogeneous small particles (average diameter $=2.7 \mathrm{~nm}$ ) after $24 \mathrm{~h}$. Preliminary study has shown that the

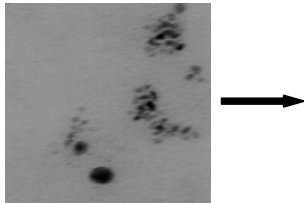

0 min

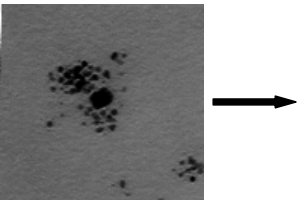

$10 \min$

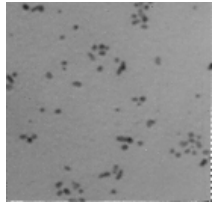

$24 \mathrm{~h}$

Fig. 3. TEM photographs of the physical mixtures of Ag and Rh nanoparticles. The aqueous solutions of Ag and Rh nanoparticles (1/1, atom-mol/atom-mol) were mixed, and dried after indicated periods. 
increase of $\mathrm{Rh} / \mathrm{Ag}$ molar ratio reduces the average diameter and the size distribution of the nanoparticles. The elemental analysis using characteristic X-ray in high-resolution TEM measurement has shown that the particles produced from their physical mixtures in $24 \mathrm{~h}$ are composed of Ag and Rh.

\subsubsection{X-ray diffraction of the of siver-core bimetallic nanoparticles}

Figure 4 shows $\mathrm{X}$-ray diffraction (XRD) patterns of poly( $N$-vinyl-2-pyrrolidone)-protected $\mathrm{Ag}$ and $\mathrm{Rh}$ monometallic nanoparticles, and their physical mixture. The sample of the physical mixture of $\mathrm{Ag}$ and $\mathrm{Rh}$ nanoparticles was prepared by drying the mixtures of their aqueous solutions under vacuum for $24 \mathrm{~h}$ after mixing. The XRD pattern of the mixtures of $\mathrm{Ag}$ and $\mathrm{Rh}$ nanoparticles was similar to that of $\mathrm{Rh}$ nanoparticle, suggesting that the surface of the particle produced by mixing $\mathrm{Ag}$ and $\mathrm{Rh}$ nanoparticles is composed of Rh. Similarly, $\mathrm{Au}$-core/Pt-shell and Au-core/Pd-shell structured nanoparticles have shown the XRD pattern quite similar to that of their surface metals (Yonezawa \& Toshima, 1995). These findings suggest that the aggregation of $\mathrm{Rh}$ particles around the Ag particle is involved in the extinction of the plasmon absorption.

\subsubsection{Mechanism of the formation of the siver-core/rhodium shell bimetallic nanoparticles}

Henglein et al. reported that lead $(\mathrm{Pb})$ atoms transfer from $\mathrm{Pb}$ colloidal particle onto the surface of Ag colloidal particle in physical mixing of $\mathrm{Ag}$ and $\mathrm{Pb}$ colloidal sols (Henglein et al., 1992). If the extinction of the plasmon absorption is due to coating of the surface of $\mathrm{Ag}$ particle by $\mathrm{Rh}$ atoms transferred from $\mathrm{Rh}$ nanoparticle, at least $28 \mathrm{~mol} \%$ of $\mathrm{Rh}$ to $\mathrm{Ag}$ is required assuming that a $\mathrm{Ag}$ particle (average diameter $=7.5 \mathrm{~nm}$ ) is uniformly coated by $\mathrm{Rh}$ atoms in a one-atom layer. In the present experiments about 40 atom-mol\% of $\mathrm{Rh}$ to $\mathrm{Ag}$ was

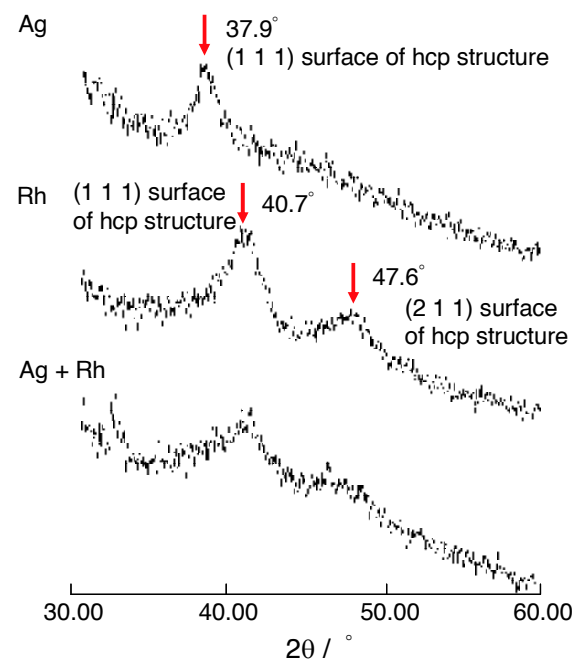

Fig. 4. XRD patterns of Ag and Rh monometallic nanoparticles, and their physical mixture (1/1, atom-mol/atom-mol) 
required to completely extinguish the plasmon absorption, which is reasonably supporting the above assumption. These observations suggest that the physical mixture of $\mathrm{Ag}$ and $\mathrm{Rh}$ nanoparticles spontaneously generates $\mathrm{Ag} / \mathrm{Rh}$ bimetallic nanoparticles with an $\mathrm{Ag}$ core/Rh-shell structure. The disappearance of the XRD peak of Ag nanoparticles suggests that the core of this bimetallic nanoparticles is not complete Ag, but possibly has a partial $\mathrm{Ag} / \mathrm{Rh}$ alloy structure. The driving force of the formation of this $\mathrm{Ag} / \mathrm{Rh}$ bimetallic nanoparticles may be due to the larger binding energy between $\mathrm{Ag}$ and $\mathrm{Rh}$ atoms than between Rh atoms (Peiner \& Kopitzki, 1998). Reduction of diameter of the nanoparticle increases not only its surface energy but also number of the binding sites between Ag and $\mathrm{Rh}$ atoms, which stabilizes the total energy. Therefore, the shrinking of $\mathrm{Ag} / \mathrm{Rh}$ bimetallic nanoparticles might be explained by the balance between the binding energy and the surface energy. The size and the rate of formation of the bimetallic nanoparticles can be controlled by the kind and concentration of protective agents. The self-assembling formation of bimetallic nanoparticle using Ag nanoparticle is applicable to construction of novel nanoparticles.

\subsection{Silver-core/noble metal-shell bimatallic nanoparticles}

The above mentioned procedure can be used to prepare the Ag-core/noble metal shell nanoparticles, other than Ag-core/Rh-shell nanoparticles. The physical mixing of Ag and other metal nanoparticles, such as $\mathrm{Au}, \mathrm{Pt}, \mathrm{Rh}$, and $\mathrm{Pd}$ particles, produces $\mathrm{Ag}$-core bimetallic particles. The interaction rate between $\mathrm{Ag}$ and other metal nanoparticles was determined by the extinction of the surface plasmon absorption of Ag nanoparticle. The initial step of this reaction was investigated by isothermal titration calorimetry (Toshima et al., 2005). This study revealed that the strength of the interaction between Ag and other metals increases in the order of $\mathrm{Rh} / \mathrm{Ag}>\mathrm{Pd} / \mathrm{Ag}>\mathrm{Pt} / \mathrm{Ag}$.

The formed Ag-core/Pt-shell nanoparticle catalyzed the decomposition of hydrogen peroxide (described later). On the other hand, $\mathrm{Au}$ and $\mathrm{Au} / \mathrm{Ag}$ nanoparticles showed an activity of photocatalytic decomposition of methylene blue (Hirakawa, 2007), although their activities were significantly smaller than that of well-known titanium dioxide photocatalyst (Fujishima et al., 2000, 2008). The physical mixing method is simple and useful to prepare novel bimetallic nanoparticles. These nanoparticles may be used as catalyst and photocatalyst.

\subsection{Application to the preparation of trimetallic nanoparticles}

This method can be applied to the preparation of trimetallic nanoparticles (Toshima et al., 2007,2011 ). It has been reported that the synthesis of trimetallic nanoparticles having a Aucore structure by a combination of the preparation of bimetallic nanoparticles by coreduction with the formation of core/shell-structured bimetallic nanoparticles by selforganization in physical mixture (Figure 5). The formation of trimetallic nanoparticles has been suggested by UV-Vis spectral change, TEM image change, FT-IR spectra of adsorbed carbon monoxide, XPS spectra and calorimetric studies. The catalytic activity of trimetallic nanoparticles in the molar ratio of $\mathrm{Au} / \mathrm{Pd} / \mathrm{Rh}=1 / 4 / 20$ was higher than the corresponding monometallic and bimetallic nanoparticles for hydrogenation of methyl acrylate. This high catalytic activity can be understood by sequential electronic charge transfer from surface $\mathrm{Rh}$ atoms to interlayered $\mathrm{Pt}$ atoms and then to core Au atoms (Toshima et al., 2011). 


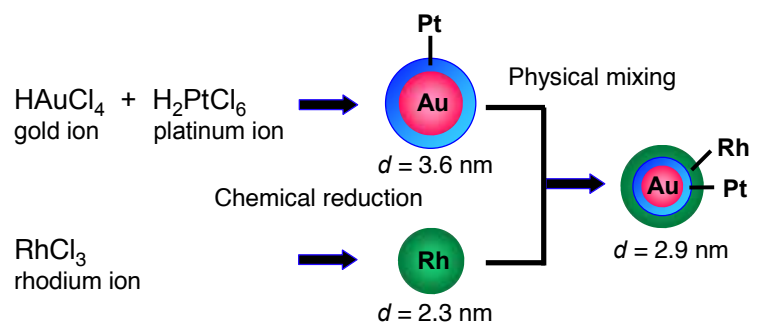

Fig. 5. Schematic diagram of the formation of the trimetallic $\mathrm{Au} / \mathrm{Pt} / \mathrm{Rh}$ nanoparticles

\section{Visible-light-induced hydrogen generation by metal nanoparticle catalytic system}

Metal nanoparticles are very important materials for nanoscience and nanotechnology (Fukumi et al., 1994; Lu et al., 1999; Link et al., 1999; Sun et al., 1999; Teranishi \& Miyake, 1999; Akinaga, 2002). A particularly large number of reports have been published on their applications to catalysts (Kiely et al., 1998; Pileni, 1998; Bradley, 1994; Widegren \& Finke 2003; Willner et al., 1987; Toshima et al., 1995; Yonezawa \& Toshima, 1993). As the catalyst in the homogeneous system, the colloidal dispersions of metal nanoparticles have the advantage that they are soluble or homogeneous in an aqueous solution and transparent to visible light (Kiely et al., 1998; Pileni, 1998; Bradley, 1994; Widegren \& Finke 2003; Willner et al., 1987). Thus, colloidal metal nanoparticles are useful for photocatalytic reaction systems. For example, colloidal metal nanoparticles catalyze the water reduction in the visible-lightinduced electron transfer system composed of ethylenediaminetetraacetic acid disodium salt (EDTA), tris(bipyridine)ruthenium(II) dichloride $\left(\left[\mathrm{Ru}(\mathrm{bpy})_{3}\right]^{2+}\right)$, and 1,1'-dimethyl-4,4'bipyridium dichloride (methyl viologen, $\mathrm{MV}^{2+}$ ) (Yonezawa \& Toshima, 1993) (Figure 6).

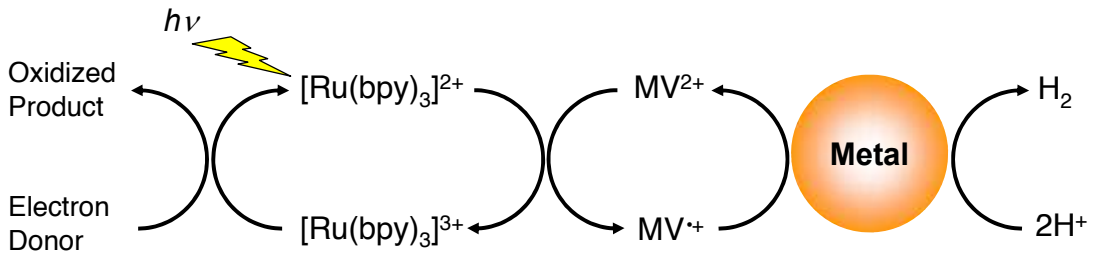

Fig. 6. Schematic diagram of the visible-light induced hydrogen generation using the electron transfer system and metal nanoparticle catalyst

\subsection{Catalytic activity of gold-core/platinum-shell bimetallic nanoparticles}

The bimetallization of metal nanoparticle can improve the catalytic activity of surface metal. Especially, core-shell structured nanoparticles are important. Several study demonstrated the Au-core/Pt shell metal nanoparticles show higher catalytic activity for the visible-lightinduced hydrogen generation than Pt monometallic nanoparticles. The following study is an example of the hydrogen generation using $\mathrm{Au} / \mathrm{Pt}$ nanoparticle catalyst (Yonezawa \& Toshima, 1993). In this study, the $\mathrm{Au} / \mathrm{Pt}$ bimetallic systems stabilized by polymer and micelle were obtained by alcohol- and photo-reduction of the corresponding metal ions in 
the presence of water-soluble polymers and non-ionic surfactant-micelles, respectively. The $\mathrm{UV}-\mathrm{Vis}$ spectra and the transmission electron micrographs suggest that the polymerprotected $\mathrm{Au} / \mathrm{Pt}$ bimetallic systems are composed of bimetallic alloy clusters, but the micelle-protected ones are mostly composed of the mixtures of the monometallic $\mathrm{Au}$ and $\mathrm{Pt}$ particles. The in-situ UV-Vis spectra during the reductions can elucidate the formation processes of the bimetallic dispersions which are different from each other depending on the protective reagent. The $\mathrm{Au} / \mathrm{Pt}$ bimetallic systems can be used as the catalyst for visible lightinduced hydrogen generation. The bimetallic system stabilized by the polymer at a molar ratio of $\mathrm{Au} / \mathrm{Pt}=2 / 3$ is the most active catalyst.

\subsection{Application of siver-core/rhodium-shell bimetallic nanoparticles}

It has been reported that the catalytic activity of the $\mathrm{Ag} / \mathrm{Rh}$ bimetallic nanoparticles for visible-light-induced hydrogen generation (Toshima \& Hirakawa, 1999) in an aqueous solution composed of ethylenediaminetetraacetic acid, tris(bipyridine)ruthenium(II), methyl viologen, and metal nanoparticle catalyst. The activity is clearly higher than the corresponding monometallic nanoparticles and alloy-structured $\mathrm{Ag} / \mathrm{Rh}$ nanoparticles, suggesting that the Ag-core shows an electronic effect on the surface Rh as in the case of the Au-core (Yonezawa \& Toshima, 1993) and enhances the catalytic activity of the surface Rh. The highest catalytic activity was observed at 1:9 ratio of Ag and Rh atoms (Figure 7). Similar results reported on the other catalytic reactions.

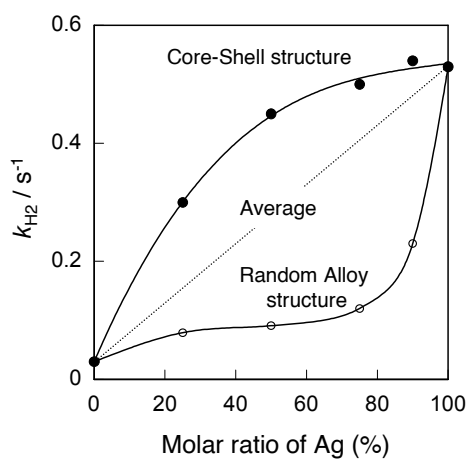

Fig. 7. Hydrogen generation rate coefficient $\left(k_{\mathrm{H} 2}\right)$ depending on the molar ratio of Ag of $\mathrm{Ag} / \mathrm{Rh}$ bimetallic nanoparticles. The $k_{\mathrm{H} 2}$ indicates the number of generated $\mathrm{H}_{2}$ molecules on a surface metal atom per one second. The average is the calculated activity of the simple mixture of $\mathrm{Ag}$ and $\mathrm{Rh}$ monometallic nanoparticles.

\subsection{Carbon dioxide reduction by visible-light-induced electron transfer system using metal nanoparticle}

A photochemical reduction of $\mathrm{CO}_{2}$ can be applied to a novel energy storage process for the utilization of solar energy in the future. The above mentioned catalytic system can be applied to $\mathrm{CO}_{2}$ reduction. The strategy is the catalytic reduction of $\mathrm{CO}_{2}$ using electrons gathered by an electron transfer system (Willner et al., 1987, Toshima et al., 1995). It has been reported that nanoparticles catalyzes the reduction of $\mathrm{CO}_{2}$ and the generation of methane (Toshima et al., 1995) (Figure 8). 


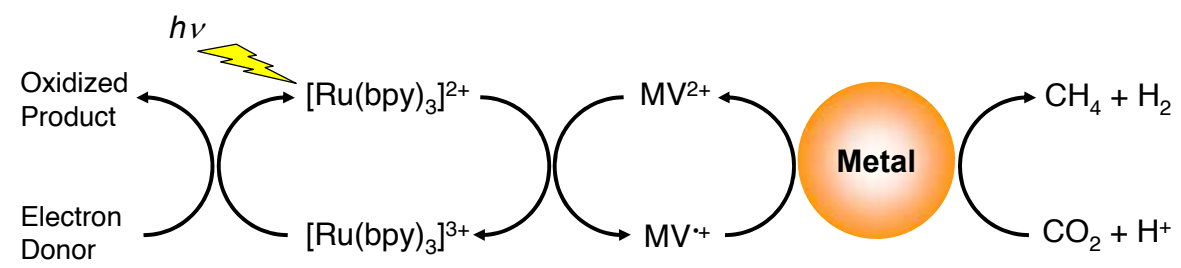

Fig. 8. Schematic diagram of the visible-light induced $\mathrm{CO}_{2}$ reduction using the electron transfer system and metal nanoparticle catalyst

The possible reaction scheme of the $\mathrm{CO}_{2}$ reduction is as follows:

$$
\mathrm{CO}_{2}+8 \mathrm{H}^{+}+8 \mathrm{e}^{-} \rightarrow \mathrm{CH}_{4}+2 \mathrm{H}_{2} \mathrm{O}
$$

This eight-electron reduction of $\mathrm{CO}_{2}$ is advantageous process compared with other possible $\mathrm{CO}_{2}$ reduction process from the thermodynamic point of view. Although it is not a study using the silver-core bimetallic nanoprticles, this topic is closely related to the applications of bimetallic nanoparticles to catalytic reaction. Thus, the topic of the $\mathrm{CO}_{2}$ reduction using metal nanoparticle catalyst is presented here.

Typical reactions were performed by the similar manner to the hydrogen generation. A 20$\mathrm{cm}^{3}$ Pyrex Schlenk tube was charged with a $10 \mathrm{~cm}^{3}$ aqueous solution, containing EDTA (a sacrificial electron donor), $\left[\mathrm{Ru}(\mathrm{bpy})_{3}\right]^{2+}$ (a photosensitizer), $\mathrm{MV}^{2+}$ (an electron mediator), $\mathrm{NaHCO}_{3}$ (a pH adjuster and a $\mathrm{CO}_{2}$ source), and colloidal dispersion of metal nanoparticles. The mixtures were degassed by freeze-thaw cycles and the tubes were then filled with $1 \mathrm{~atm}$ of $\mathrm{CO}_{2}$. The photo-irradiation was carried out for 3 or $4 \mathrm{~h}$ with a $500 \mathrm{~W}$ super-high-pressure mercury lamp through a UV cut filter $(>390 \mathrm{~nm})$ in a water bath maintained at $30^{\circ} \mathrm{C}$. About $100 \mu \mathrm{mol}$ of methane was detected in this system (Toshima et al., 1995). However, it has not been confirmed that methane was actually the reduction product of $\mathrm{CO}_{2}$.

\subsubsection{Strategy for the demonstration of the methane generation from carbon dioxide}

In a heterogeneous system, photoreduction of $\mathrm{CO}_{2}$ was confirmed by experiments using an isotope (Ishitani et al. 1993). To our knowledge, however, the isotopic method has not been applied to the confirmation of the photoreduction of $\mathrm{CO}_{2}$ in a homogeneous system using the colloidal dispersion of metal nanoparticles. To confirm the above mentioned methane generation, the following study was carried out. In this study, photoreduction of $\mathrm{CO}_{2}$ was carried out in a similar system to one reported previously (Toshima et al., 1995), and the generation of methane from $\mathrm{CO}_{2}$ was confirmed by isotopic experiments. As the catalysts, novel metal nanoparticles, i.e., liposome-protected Pt nanoparticles, were prepared and used in the present system. Colloidal dispersions of $\mathrm{Pt}$ and $\mathrm{Ru}$ nanoparticles were prepared by photoreduction without using ethanol (Yamaji et al. 1995). Preparation of nanoparticles without ethanol is required, because the coexisting ethanol is decomposed during the photochemical reaction, leading to the formation methane. This methane formation cannot be distinguished from the actual methane generation from $\mathrm{CO}_{2}$. Protective agents used for the metal nanoparticles were poly( $N$-vinyl-2-pyrrolidone), $\mathrm{C}_{12} \mathrm{EO}$, and liposome. The products in the gas phase were analyzed with a gas chromatograph. The characterization of gaseous products was carried out with a gas chromatograph mass-spectrometer. 


\subsubsection{Methane generation from carbon dioxide reduction}

The formation of methane was then clearly detected by gas chromatography (about 19 nmol in the case of the liposome protected $\mathrm{Pt}$ nanoparticles system). In order to confirm the methane generation from $\mathrm{CO}_{2}$, isotope experiments were carried out using $\mathrm{NaH}^{13} \mathrm{CO}_{3}$ as a $\mathrm{CO}_{2}$ source and analyzed by a gas chromatograph mass-spectrometer. Since $\mathrm{NaHCO}_{3}$ is equilibrated with $\mathrm{CO}_{2}$ in solution and easily treated, it was a good source of $\mathrm{CO}_{2}$ in the present experiments. In this experiment, ${ }^{13} \mathrm{CH}_{4}$ was clearly detected, though the produced methane was not pure ${ }^{13} \mathrm{CH}_{4}$ and it did contain ${ }^{12} \mathrm{CH}_{4}$. In the same experiment, the mole ratio of ${ }^{13} \mathrm{CO}_{2}$ to ${ }^{12} \mathrm{CO}_{2}$ in the gas phase was about $57: 43$, which is nearly the same as the isotopic ratio of the generated methane. EDTA works as an electron donor in the system and is known to decompose into $\mathrm{CO}_{2}$. Therefore, ${ }^{12} \mathrm{CH}_{4}$ generation possibly occurs through the reduction of ${ }^{12} \mathrm{CO}_{2}$ generated from EDTA. The effect of EDTA on methane generation was examined in the Pt-liposome system. Methane was detected on visible-light irradiation of the system involving EDTA without $\mathrm{CO}_{2}$ or $\mathrm{NaHCO}_{3}$ but could not be detected in the absence of EDTA. These results suggest that the detected ${ }^{12} \mathrm{CH}_{4}$ is generated by the reduction of ${ }^{12} \mathrm{CO}_{2}$ originated from EDTA.

\subsubsection{Liposome-protected metal nanoparticle catalyst}

Liposome was better than other protective-colloid of $\mathrm{Pt}$ nanoparticles for methane generation. This is probably explained by assuming that liposome can form a larger and stronger hydrophobic region to concentrate $\mathrm{CO}_{2}$ around a $\mathrm{Pt}$ nanoparticle than $\mathrm{C}_{12} \mathrm{EO}$ micelle and poly( $N$-vinyl-2-pyrrolidone). In addition, $\mathrm{Ru}-\mathrm{C}_{12} \mathrm{EO}$ showed higher catalytic activity than $\mathrm{Pt}-\mathrm{C}_{12} \mathrm{EO}$. Thus, Ru-liposome was considered to be an active catalyst for methane generation in the system tested here. The synthesis of Ru-liposome was tried in a way similar to that of Pt-liposome, but the suspension of the Ru-liposome was not active as a catalyst. The resulting Ru-liposome was not as homogeneous, probably because the Ru ion is not miscible with liposome in water.

\subsubsection{Summary of the carbon dioxide photo-reduction by metal nanoparticle catalyst}

The Pt and Ru nanoparticle catalysts, which were prepared by a photoreduction method of metal salt in water without ethanol, successfully generated methane from $\mathrm{CO}_{2}$. The methane generation suggests that the eight-electron reduction of $\mathrm{CO}_{2}$ easily proceeds on metal nanoparticles possibly due to a thermodynamic advantage. This is different from an electrochemical $\mathrm{CO}_{2}$ reduction using Pt electrodes, on which $\mathrm{CO}_{2}$ is reduced to $\mathrm{CO}$ with adsorbed hydrogen atoms. In the present system using metal nanoparticles, the competition reaction, i.e., the kinetically favorably hydrogen generation, inhibits the methane generation. An increase of $\mathrm{CO}_{2}$ concentration, the electron supply rate, or both may enhance $\mathrm{CO}_{2}$ reduction.

\section{Catalytic decomposition of hydrogen peroxide by metal nanoparticle}

The modification of biomacromolecules upon exposure to reactive oxygen species, including hydrogen peroxide $\left(\mathrm{H}_{2} \mathrm{O}_{2}\right)$, dioxide(1-) (superoxide $\mathrm{O}_{2}{ }^{\bullet}$ ), hydroxyl radical $\left(\mathrm{HO}^{\bullet}\right)$, and singlet oxygen $\left({ }^{1} \mathrm{O}_{2}\right)$, is the likely initial event involved in the induction of the mutagenic and lethal effects of various oxidative stress agents (Kawanishi et al. 2001; Cadet et al., 2003; 
Drechsel \& Patel, 2008). Therefore, the activity of reactive oxygen species generation by various chemical compounds is closely related to their toxicity, carcinogenicity, or both. For example, hydroquinone, a metabolite of carcinogenic benzene, causes DNA damage via $\mathrm{H}_{2} \mathrm{O}_{2}$ generation (Hirakawa et al., 2002). Many studies have addressed the role of antioxidants, such as vitamins (Slaga, 1995; Sohmiya et al., 2004) and catechins (Weyant et al., 2001), in protection against cancers and cardiovascular diseases. These antioxidants can scavenge reactive oxygen species and protect against cancer occurrence. On the other hand, every antioxidant is in fact, a redox agent, protecting against reactive oxygen species in some circumstances and promoting free radical or secondary reactive oxygen species generation in others. Indeed, an excess of these antioxidants elevates the incidence of cancer (Nitta et al. 1991; Omenn et al., 1996). Solovieva et al. reported that antioxidants, ascorbic acid (Solovieva et al., 2007) and dithiothreitol (Solovieva et al., 2008), exhibit cytotoxicity via $\mathrm{H}_{2} \mathrm{O}_{2}$ generation. Relevantly, it has been reported that vitamins A (Murata \& Kawanishi, 2000) and E (Yamashita et al., 1998) and catechins (Oikawa et al., 2003) induce DNA oxidation through $\mathrm{H}_{2} \mathrm{O}_{2}$ generation during their oxidation. $\mathrm{H}_{2} \mathrm{O}_{2}$ is a long-lived reactive oxygen species which plays an important role in biomacromolecular damage induced by various chemical compounds (Kawanishi et al., 2001; Hirakawa et al., 2002).

\subsection{Metal catalyzes decomposition of hydrogen peroxide}

Various studies have demonstrated the catalytic decomposition of $\mathrm{H}_{2} \mathrm{O}_{2}$ by noble metals such as Pt (Keating et al., 1965; McKee, 1969; Bianchi et al., 1962), Pd (Keating et al., 1965; McKee, 1969; Bianchi et al., 1962; Eley \& Macmahon, 1972) Ag (Baumgartner et al., 1963; Goszner et al., 1972; Goszner \& Bischof, 1974), and Au (Eley \& Macmahon, 1972; Goszner \& Bischof, 1974). These metals themselves are hardly oxidized by reactive oxygen species, however, it is difficult to use metal powder or foils as anti-oxidative drugs. Recently, Kajita et al. reported that $\mathrm{Pt}$ nanoparticles catalyze the decomposition of reactive oxygen species (Kajita et al., 2007). These nanoparticles can be dispersed in water and used as homogenous solutions. Because this removal mechanism is catalytic decomposition, no oxidized product is formed through this reaction. Platinum metal is used as a food additive and is not considered to be a toxic material. This result led us to the idea that inorganic materials, in particular noble metals, rather than organic antioxidants, can be used as novel chemopreventive agents against reactive oxygen species-mediated biomolecules damage. In this section, the examination of the removal of $\mathrm{H}_{2} \mathrm{O}_{2}$ generated from a chemical compound, hydroquione, using water-soluble polymer-protected $\mathrm{Pt}$ and $\mathrm{Ag} / \mathrm{Pt}$ nanoparticles are reviewed.

\subsection{Catalytic activity of monometallic nanoparticles}

\subsubsection{Preparation of metal nanoparticles for reactive oxygen scavenger}

Colloidal dispersions of poly( $N$-vinyl-2-pyrrolidone)-protected $\mathrm{Pt}, \mathrm{Pd}, \mathrm{Rh}$, and $\mathrm{Au}$ nanoparticles were prepared using an alcohol reduction method (Hirai et al., 1979). $50 \mathrm{~mL}$ of water/ethanol (1/1, v/v) solution containing $1 \mathrm{mM}$ metal salts and $40 \mathrm{mM}$ poly(N-vinyl-2pyrrolidone) (monomer unit) was refluxed for $2 \mathrm{~h}$, resulting in the formation of typical colored sols of metal nanoparticles. The solvent was removed by vacuum evaporation, and the nanoparticles were dispersed into water to prepare $1 \mathrm{mM} /$ atom (atomic concentration) metal colloidal sols. An aqueous solution of poly( $N$-vinyl-2-pyrrolidone)-protected Ag 
nanoparticles (Shiraishi \& Toshima, 1999) was prepared from reduction of $1 \mathrm{mM} \mathrm{AgNO}_{3}$ with $\mathrm{NaBH}_{4}$ in the presence of $40 \mathrm{mM}$ poly( $N$-vinyl-2-pyrrolidone). The obtained $\mathrm{Ag}$ colloidal dispersion was purified with an ultra-filter.

These poly( $N$-vinyl-2-pyrrolidone)-protected metal nanoparticles formed water-soluble sols. The average diameters $(d)$ and standard deviations $(\sigma)$ of monometallic nanoparticles determined by TEM measurement were as follows: $\operatorname{Pt}(d=2.2 \mathrm{~nm}, \sigma=1.0 \mathrm{~nm}), \operatorname{Pd}(d=2.0$ $\mathrm{nm}, \sigma=0.9 \mathrm{~nm}), \operatorname{Rh}(d=2.2 \mathrm{~nm}, \sigma=1.0 \mathrm{~nm}), \operatorname{Ag}(d=10.0 \mathrm{~nm}, \sigma=1.9 \mathrm{~nm})$, and Au $(d=10.2 \mathrm{~nm}$, $\sigma=2.0 \mathrm{~nm})$.

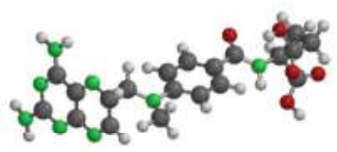

Folic acid
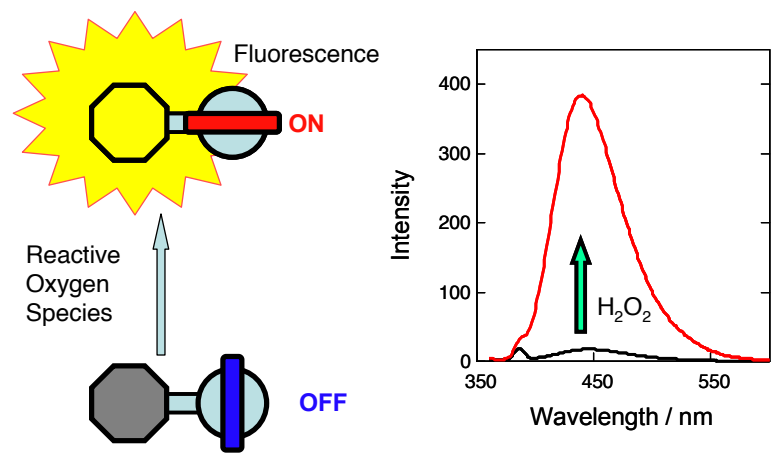

Fig. 9. Fluorometry of reactive oxygen species (hydrogen peroxide) using folic acid

\subsubsection{Method of the detection of hydrogen peroxide}

The generated $\mathrm{H}_{2} \mathrm{O}_{2}$ was measured by a previously reported method using folic acid (Hirakawa, 2006). This assay is based on the fluorescence enhancement of less-fluorescent folic acid via oxidative decomposition by $\mathrm{H}_{2} \mathrm{O}_{2}$ and copper(II) ion into strong-fluorescent 2amino-4-oxo-3H-pterine-6-carboxylic acid (Figure 9). The concentration of $\mathrm{H}_{2} \mathrm{O}_{2}\left(\left[\mathrm{H}_{2} \mathrm{O}_{2}\right]\right)$ can be determined using a calibration curve. A reaction mixture containing folic acid, copper(II) chloride, and the $\mathrm{H}_{2} \mathrm{O}_{2}$ sample (or $\mathrm{H}_{2} \mathrm{O}_{2}$ generator ${ }^{4}$ ) with or without the metal nanoparticle in a sodium phosphate buffer $(\mathrm{pH} 7.6)$ was incubated in a microtube for $30 \mathrm{~min}$. After incubation at $37{ }^{\circ} \mathrm{C}$, the fluorescence intensity of the reaction mixture at $450 \mathrm{~nm}$ was measured using a fluorescence spectrophotometer with 350-nm excitation.

\subsubsection{Platinum nanoparticles effectively scavenge hydrogen peroxide}

Platinum nanoparticles effectively scavenged $\mathrm{H}_{2} \mathrm{O}_{2}$ in a dose-dependent manner and showed the highest activity among the metal nanoparticles used in this study (Figure 10). A sample solution of $5 \mu \mathrm{M}$ /atom Pt nanoparticles, among which $1 \mu \mathrm{g}$ Pt metal is included, exhibits comparable activity for $\mathrm{H}_{2} \mathrm{O}_{2}$ decomposition to that of 10 units of catalase. One unit of catalase can remove $1.0 \mu \mathrm{mol} \mathrm{H}_{2} \mathrm{O}_{2}$ per min in water $\left(\mathrm{pH} 7.0,25{ }^{\circ} \mathrm{C}\right)$. Poly $(\mathrm{N}$-vinyl-2pyrrolidone) itself did not scavenge $\mathrm{H}_{2} \mathrm{O}_{2}$. This experiment confirmed that poly( $\mathrm{N}$-vinyl-2pyrrolidone)-protected $\mathrm{Pt}$ nanoparticles can remove $\mathrm{H}_{2} \mathrm{O}_{2}$. The mechanism of $\mathrm{H}_{2} \mathrm{O}_{2}$ removal by $\mathrm{Pt}$ nanoparticles can be explained by catalytic decomposition into water and molecular oxygen as follows: 


$$
\mathrm{H}_{2} \mathrm{O}_{2} \rightarrow \mathrm{H}_{2} \mathrm{O}+1 / 2 \mathrm{O}_{2}
$$

The generation of $\mathrm{O}_{2}$ gas through the $\mathrm{H}_{2} \mathrm{O}_{2}$ decomposition was confirmed with a gas-burette as following procedure. The $10 \mathrm{~mL}$ of aqueous solution containing $0.1 \mathrm{M} \mathrm{H}_{2} \mathrm{O}_{2}$ was treated by $10 \mu \mathrm{g} \mathrm{Pt}$ nanoparticles and generated $\mathrm{O}_{2}$ gas was measured with a gas-burette. The volume of detected gas coincided with that of the theoretically calculated value of $\mathrm{O}_{2}$ generation from the decomposition of $\mathrm{H}_{2} \mathrm{O}_{2}$ in the sample solution.

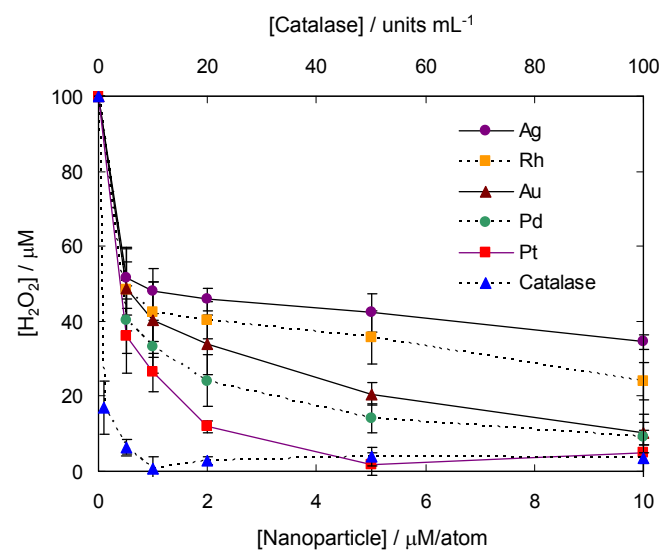

Fig. 10. Removal of $\mathrm{H}_{2} \mathrm{O}_{2}$ by metal nanoparticles and catalase. The $1 \mathrm{~mL}$ of sample solution containing $100 \mu \mathrm{M} \mathrm{H}_{2} \mathrm{O}_{2}, 10 \mu \mathrm{M}$ folic acid, $20 \mu \mathrm{M}$ copper(II) chloride, and indicated concentration of metal nanoparticles or catalase was incubated for $30 \mathrm{~min}$. The concentration of $\mathrm{H}_{2} \mathrm{O}_{2}$ was estimated from the fluorescence measurement.

\subsection{Application of siver-core/platinum-shell bimetallic nanoparticles to catalytic decomposition of hydrogen peroxide generated by chemical compound}

\subsubsection{Preparation of silver-core bimetallic nanoparticles for hydrogen peroxide scavenger}

The catalytic activity of $\mathrm{Pt}$ and its modified particles with $\mathrm{Ag}(\mathrm{Ag} / \mathrm{Pt})$ on the decomposition of $\mathrm{H}_{2} \mathrm{O}_{2}$ generated from chemical compounds was evaluated, since Pt showed the highest activity. The $\mathrm{Ag} / \mathrm{Pt}$ nanoparticles were prepared from the following procedure. The absorption spectrum of the sol of $\mathrm{Pt}$ nanoparticles is a flat curve (Figure 11), indicating the formation of homogenous particles. Ag nanoparticles exhibited a typical yellow color due to surface plasmon absorption around $400 \mathrm{~nm}$. It has been reported that a physical mixture of Ag and Pt nanoparticles spontaneously forms bimetallic nanoparticles, possibly Ag-core/Ptshell structured particles (Toshima et al., 2005). The time-course of the absorption spectra of this physical mixture showed the extinction of Ag surface plasmon absorption, and the absorption was completely extinguished within $24 \mathrm{~h}$ (Figure 11), suggesting that the surface of the formed bimetallic nanoparticles is composed of $\mathrm{Pt}$ atoms. Typical TEM images showed the formation of relatively small particles of $\mathrm{Pt}$ and large particles of Ag (Figure 12). TEM photographs showed that the large Ag particles disappeared through interaction with $\mathrm{Pt}$ particles, resulting in the formation of bimetallic particles smaller than the parent $\mathrm{Ag}$ particles (Figure 12). A similar result has been observed in the case of $\mathrm{Ag} / \mathrm{Rh}$ bimetallic 
nanopaticles (Toshima \& Hirakawa, 2003). These findings suggest the formation of selforganized Ag/Pt bimetallic nanoparticles. These metal nanoparticles are stable in water for several months. The Ag/Pt (Ag-atom/Pt-atom, 1/1) bimetallic nanoparticles were prepared using a self-organization method to mix $\mathrm{Pt}$ and $\mathrm{Ag}$ monometallic nanoparticles according to previous reports (Toshima \& Hirakawa, 2003; Toshima et al., 2002, 2005; Matsushita et al., 2007).

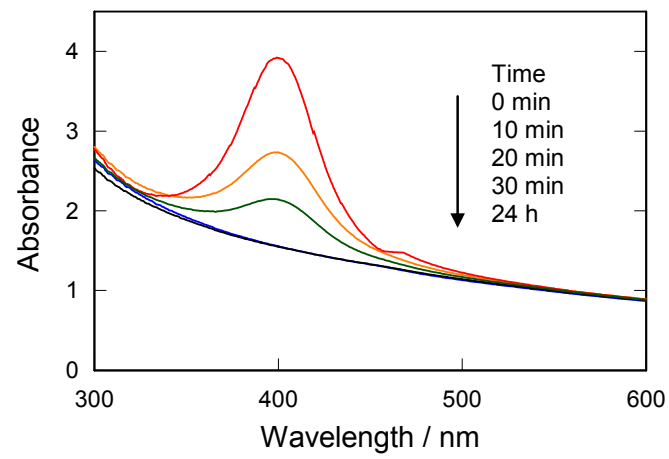

Fig. 11. Absorption spectral change of the physical mixture of dispersions of $\mathrm{Ag}$ and $\mathrm{Pt}$ nanoparticles. The aqueous solutions of $\mathrm{Ag}(1 \mathrm{mM} /$ atom, $10 \mathrm{~mL})$ and $\mathrm{Pt}(1 \mathrm{mM} /$ atom, 10 $\mathrm{mL}$ ) nanoparticles were mixed and measured at $0,10,20$, and $30 \mathrm{~min}$, and $24 \mathrm{~h}$ after mixing.

(A) Pt

Average diameter: $d=2.2 \mathrm{~nm}$ Standard Deviation: $\sigma=1.0 \mathrm{~nm}$

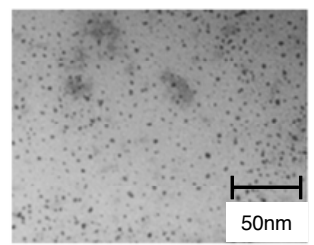

(B) $\mathrm{Ag}$

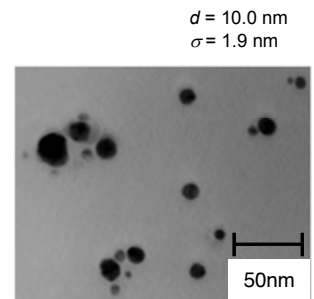

(C) $\mathrm{Ag} / \mathrm{Pt}$ $d=2.6 \mathrm{~nm}$ $\sigma=1.6 \mathrm{~nm}$

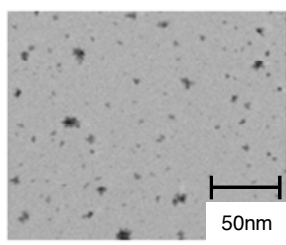

Fig. 12. TEM photographs of metal nanoparticles. The sample of Ag/Pt nanoparticles was prepared by drying the mixtures of the aqueous solutions of $\mathrm{Pt}$ and $\mathrm{Ag}$ monometallic nanoparticles 24 hour after mixing.

\subsubsection{Hydrogen peroxide formation from hydroquinone and its removal by metal nanoparticles}

Hydroquinone, which is a metabolite of carcinogenic benzene, was used as $\mathrm{H}_{2} \mathrm{O}_{2}$ source. This compound can generate $\mathrm{H}_{2} \mathrm{O}_{2}$ through autooxidation (Figure 13) (Hirakwa et al., 2002). Under these experimental conditions, hydroquinone generated $\mathrm{H}_{2} \mathrm{O}_{2}$ in a dose-dependent manner (Figure 14). Twenty units/mL catalase effectively removed $\mathrm{H}_{2} \mathrm{O}_{2}$ generated from this system, and $10 \mu \mathrm{M} /$ atom $(2 \mu \mathrm{g} / \mathrm{mL})$ Pt nanoparticles exhibited a comparable activity to that of this catalase. Silver nanoparticles showed apparently weaker activity for $\mathrm{H}_{2} \mathrm{O}_{2}$ removal than $\mathrm{Pt}$ nanoparticles. The bimetallization of $\mathrm{Pt}$ with $\mathrm{Ag}$ apparently suppressed the catalytic activity per unit atom. 


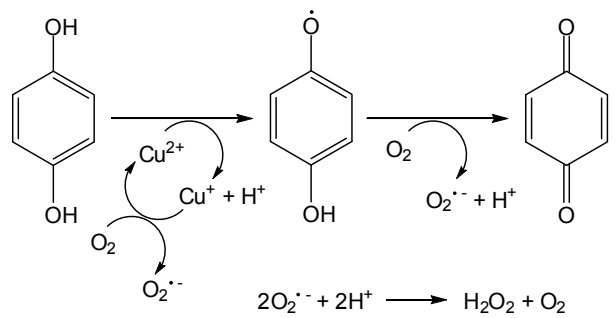

Fig. 13. Schematic diagram of hydrogen peroxide formation by the autooxidation of hydroquinone

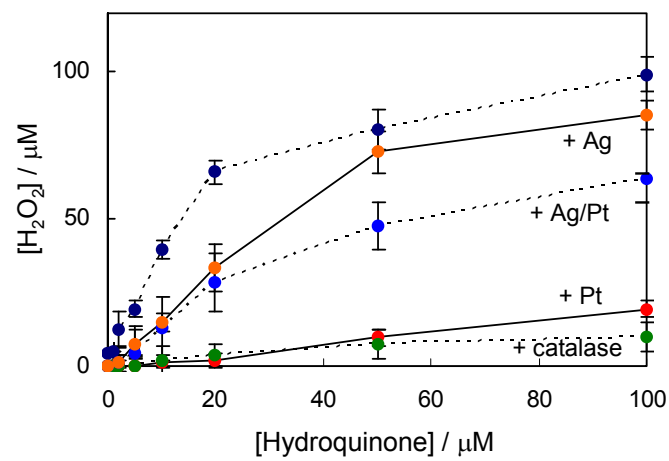

Fig. 14. $\mathrm{H}_{2} \mathrm{O}_{2}$ generation through autooxidation of hydroquinone in the absence or presence of metal nanoparticles and catalase. The $1 \mathrm{~mL}$ of sample solution containing $10 \mu \mathrm{M}$ folic acid, $20 \mu \mathrm{M}$ copper(II) chloride, and indicated concentration of hydroquinone with or without $10 \mu \mathrm{M}$ /atom metal nanoparticles or 20 units/mL catalase was incubated for $30 \mathrm{~min}$. The concentration of generated $\mathrm{H}_{2} \mathrm{O}_{2}$ was estimated from the fluorescence measurement.

\subsubsection{Activity of silver-core/platinum-shell nanoparticles on hydrogen peroxide decomposition}

Figure 15 shows the removal activity of $\mathrm{H}_{2} \mathrm{O}_{2}$ generated from a high concentration of hydroquinone $(50 \mu \mathrm{M})$ by metal nanoparticles. These metal nanoparticles and catalase scavenged $\mathrm{H}_{2} \mathrm{O}_{2}$ in a dose-dependent manner. The activity of the $10 \mu \mathrm{M} /$ atom $(2 \mu \mathrm{g} / \mathrm{mL}) \mathrm{Pt}$ nanoparticles was comparable to that of 20 units/mL catalase, and Pt completely scavenged $\mathrm{H}_{2} \mathrm{O}_{2}$ over $20 \mu \mathrm{M} /$ atom $(4 \mu \mathrm{g} / \mathrm{mL})$. The activity per atom of the $\mathrm{Ag} / \mathrm{Pt}$ bimetallic nanoparticles was almost the same as that of the $\mathrm{Ag}$ monometallic nanoparticles.

To investigate the effect of $\mathrm{Pt}$ nanoparticles on $\mathrm{H}_{2} \mathrm{O}_{2}$ generation through the autooxidation of hydroquinone, NADH consumption during this autooxidation was measured. The consumption of NADH during the autooxidation of hydroquinone was measured by a previously reported method (Oikawa et al., 2003). A sample solution containing $100 \mu \mathrm{M}$ $\mathrm{NADH}, 50 \mu \mathrm{M}$ hydroquinone, and $20 \mu \mathrm{M}$ copper(II) chloride was incubated at $37^{\circ} \mathrm{C}$ in the absence or presence of $20 \mu \mathrm{M}$ /atom Pt nanoparticles. The concentration of NADH was determined by the measurement of absorbance of NADH at $340 \mathrm{~nm}$ using a microplate 
absorbance reader. The oxidized form of hydroquinone can be reduced into the parent hydroquinone by NADH (Hirakwa et al., 2002). The concentration of NADH was gradually decreased through the redox of hydroquinone and Pt nanoparticles hardly inhibited NADH consumption (data not shown). This result indicated that Pt nanoparticles do not inhibit the $\mathrm{H}_{2} \mathrm{O}_{2}$ generation itself, because $\mathrm{H}_{2} \mathrm{O}_{2}$ is produced through the autooxidation of hydroquinone.

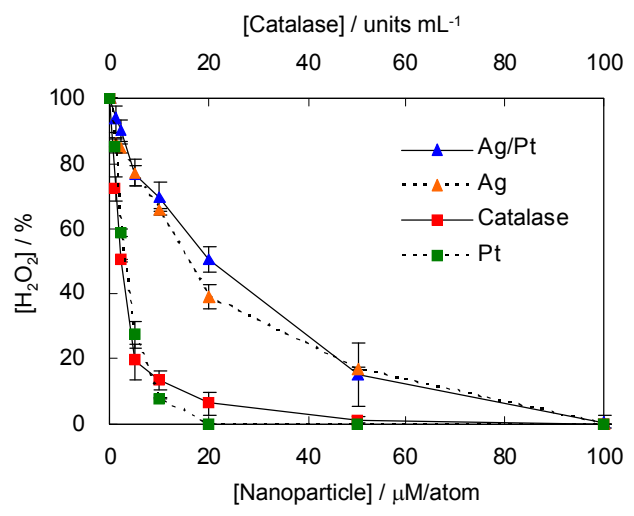

Fig. 15. Removal of $\mathrm{H}_{2} \mathrm{O}_{2}$ generated through the autooxidation of hydroquinone by metal nanoparticles and catalase. The $1 \mathrm{~mL}$ of sample solution containing $10 \mu \mathrm{M}$ folic acid, $20 \mu \mathrm{M}$ copper(II) chloride, $50 \mu \mathrm{M}$ hydroquinone, and indicated concentration of metal nanoparticles or catalase was incubated for $30 \mathrm{~min}$. The concentration of $\mathrm{H}_{2} \mathrm{O}_{2}$ was estimated from the fluorescence measurement.

\subsection{Summary and possible mechanism of hydrogen peroxide decomposition by metal nanoparticles}

Poly(N-vinyl-2-pyrrolidone)-protected metal nanoparticles, in particular Pt nanoparticles, exhibited a removal effect on $\mathrm{H}_{2} \mathrm{O}_{2}$ generated through autooxidation of hydroquinone (Figure 16). The removal of $\mathrm{H}_{2} \mathrm{O}_{2}$ by these metal nanoparticles can be explained by a catalytic reaction similar to that by catalase, which decomposes $\mathrm{H}_{2} \mathrm{O}_{2}$ into $\mathrm{H}_{2} \mathrm{O}$ and $\mathrm{O}_{2}$. The formation of $\mathrm{H}_{2} \mathrm{O}_{2}$ during autooxidation of hydroquinone is through $\mathrm{O}_{2}{ }^{\bullet-}$, which is generated from a reduction of $\mathrm{O}_{2}$ by hydroquinone (Hirakawa et al., 2002). Because the lifetime of $\mathrm{O}_{2}{ }^{\bullet-}$, which dismutates into $\mathrm{H}_{2} \mathrm{O}_{2}$ through reaction with $\mathrm{H}^{+}$, is short $(\sim 0.1 \mathrm{~ms})$, the scavenging of $\mathrm{O}_{2}{ }^{\bullet}$ - by a metal nanoparticle can be negligible. The $\mathrm{H}_{2} \mathrm{O}_{2}$ removal activity per metal atom of these metal nanoparticles occurred in the following order: $\mathrm{Pt}>$ $\mathrm{Ag} \approx \mathrm{Ag} / \mathrm{Pt}$. The activities of $\mathrm{H}_{2} \mathrm{O}_{2}$ decomposition per metal atom consisting of these metal nanoparticles $\left(\mu \mathrm{M}-\mathrm{H}_{2} \mathrm{O}_{2} / \mu \mathrm{M}\right.$-nanometal $)$ have been estimated, and the resulting values are 4.2, 12.2, and 3.8 for $\mathrm{Ag}, \mathrm{Pt}$, and $\mathrm{Ag} / \mathrm{Pt}$, respectively. Further, the activity on the surface area of the $\mathrm{Ag} / \mathrm{Pt}$ nanoparticles $\left(17 \mu \mathrm{M}-\mathrm{H}_{2} \mathrm{O}_{2} / \mathrm{cm}^{2}\right.$-nanometal) was also smaller than that of $\mathrm{Pt}\left(49 \mu \mathrm{M}-\mathrm{H}_{2} \mathrm{O}_{2} / \mathrm{cm}^{2}\right.$-nanometal). These findings showed that the $\mathrm{Pt}$ nanoparticles have the highest catalytic activity for $\mathrm{H}_{2} \mathrm{O}_{2}$ decomposition in the metal nanoparticles used in this experiment and the activity of $\mathrm{Pt}$ nanoparticles is suppressed by modification with Ag. 


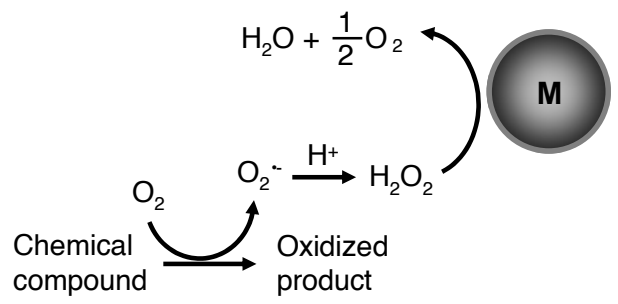

Fig. 16. Hydrogen peroxide generation from an autooxidation of chemical compound and its catalytic decomposition by metal nanoparticle

$\mathrm{H}_{2} \mathrm{O}_{2}$ is a long-lived reactive oxygen species and plays an important role in DNA damage (Kawanishi et al., 2001, Hirakawa et al., 2002). Indeed, various chemical compounds, including carcinogens, generate $\mathrm{H}_{2} \mathrm{O}_{2}$ during redox reaction (Kawanishi et al., 2001, Hirakawa et al., 2002). Molecular oxygen is easily reduced by various compounds, leading to the formation of $\mathrm{O}_{2}{ }^{\bullet}$. Formed $\mathrm{O}_{2}{ }^{-}$is rapidly dismutated into $\mathrm{H}_{2} \mathrm{O}_{2}$. Although $\mathrm{H}_{2} \mathrm{O}_{2}$ itself is not a strong reactive species, it can generate highly reactive $\mathrm{HO}^{*}$ through a Fenton reaction or a Haber-Weiss reaction. Furthermore, $\mathrm{H}_{2} \mathrm{O}_{2}$ can penetrate a cytoplasm membrane and be incorporated into the cell nucleus. Therefore, $\mathrm{H}_{2} \mathrm{O}_{2}$ is considered to be one of the most important reactive species or a precursor participating in carcinogenesis. The removal of $\mathrm{H}_{2} \mathrm{O}_{2}$ is an effective method for cancer chemoprevention. Furthermore, protective agents against $\mathrm{H}_{2} \mathrm{O}_{2}$ are important to treat acatalasemia, a genetic deficiency of erythrocyte catalase inherited as an autosomal recessive trait. Antioxidants, such as vitamins $\mathrm{A}$ and $\mathrm{E}$, are effective protective agents. However, the oxidized products of antioxidants or these molecules themselves promote the formation of secondary $\mathrm{H}_{2} \mathrm{O}_{2}$ (Yamashita et al., 1998; Murata \& Kawanishi, 2000). Indeed, an excess of these antioxidants elevates the incidence of cancer (Nitta et al., 1991; Omenn et al., 1996). A catalyst consisting of an inorganic stable material is not oxidized and does not generate secondary reactive oxygen species. Water-soluble nanoparticles of noble metal may become novel protective agents against reactive oxygen species.

In summary, $\mathrm{Pt}, \mathrm{Ag}$, and $\mathrm{Ag} / \mathrm{Pt}$ nanoparticles effectively scavenge $\mathrm{H}_{2} \mathrm{O}_{2}$ generated from autooxidation of a highly concentrated hydroquinone. Platinum nanoparticles exhibited the highest catalytic activity among these nanoparticles. Pt is a very stable metal against various chemical compounds and permitted as a food additives. The noble metal nanoparticles may be used as novel chemopreventive agents for cancer or other non-malignant conditions induced by chemical compounds through $\mathrm{H}_{2} \mathrm{O}_{2}$ generation.

\section{Application of metal nanoparticles to prevention of ultraviolet radiation induced biomolecules damage}

Exposure to solar ultraviolet radiation is undoubtedly linked to skin carcinogenesis and phototoxic effect. Photosensitized reaction by ultraviolet radiation, especially ultraviolet-A (UVA) radiation $(320 \sim 400 \mathrm{~nm})$, is considered to cause toxic effect through oxidative biomolecules damage including DNA damage (Hiraku et al., 2007). Photosensitized formation of reactive oxygen species, such as hydrogen peroxide, superoxide, hydroxyl radicals, and singlet oxygen, is involved in UVA-induced biomolecules damage. As 
mentioned above, the application of metal nanoparticles to scavenge reactive oxygen species through catalytic decomposition.

\subsection{Traditional methods of chemoprevention to biomolecules damage by ultraviolet radiation and its problem}

Many studies have addressed the role of antioxidants, such as vitamins and catechins, in protection against cancers and cardiovascular diseases. These antioxidants can scavenge reactive oxygen species and protect against cancer occurrence. On the other hand, every antioxidant is, in fact, a redox agent, protecting against reactive oxygen species in some circumstances and promoting free radical or secondary reactive oxygen species generation in others. Indeed, an excess of these antioxidants elevates the incidence of cancer. It has been reported that antioxidants, ascorbic acid and dithiothreitol, exhibit cytotoxicity via $\mathrm{H}_{2} \mathrm{O}_{2}$ generation, and their toxic effects are significantly enhanced by vitamin $\mathrm{B}_{12} . \mathrm{H}_{2} \mathrm{O}_{2}$ is a longlived reactive oxygen species which plays an important role in biomacromolecules damage induced by various chemical compounds.

\subsection{Preventive action of metal nanoparticles on ultraviolet-sensitized oxidation of molecules}

As mentioned above, metal nanoparticles catalyze the decomposition of reactive oxygen species. Because this removal mechanism is catalytic decomposition, no oxidized product is formed through this reaction. Platinum metal is used as a food additive and is not considered to be a toxic material. This result led us to the idea that inorganic materials, in particular noble metals, rather than organic antioxidants, can be used as novel chemopreventive agents against UVA-induced biomolecules damage.

Recently, it has been reported that the removal of reactive oxygen species generated from a photocatalytic reaction of titanium dioxide $\left(\mathrm{TiO}_{2}\right)$ particles using water-soluble polymerprotected $\mathrm{Pt}, \mathrm{Rh}$, and $\mathrm{Pt} / \mathrm{Ag}$ bimetallic nanoparticles. Silver, a relatively inexpensive noble metal, is also used as a food additive, and bimetallization with Ag may improve the catalytic activity of other metal nanoparticles.

\subsubsection{Preparation of metal nanoparticles for ultraviolet protection}

The colloidal dispersions of poly( $\mathrm{N}$-vinyl-2-pyrrolidone)-protected $\mathrm{Pt}$ and $\mathrm{Rh}$ nanoparticles were prepared from an alcohol reduction. The size (particle diameter) of these nanoparticles is about $2 \mathrm{~nm}$. The aqueous solution of poly( $\mathrm{N}$-vinyl-2-pyrrolidone)-protected $\mathrm{Ag}$ nanoparticle was prepared from a reduction of silver nitrate by sodium borohydride in the presence of poly(N-vinyl-2-pyrrolidone). The Ag-core/Pt-shell (Ag-atom/Pt-atom, 1/1) bimetallic nanoparticle was prepared using a physical method to mix $\mathrm{Pt}$ and $\mathrm{Ag}$ monometallic nanoparticles according to the previous reports (Toshima et al., 2005).

\subsubsection{Evaluation model for the biomolecules damage by ultraviolet radiation}

$\mathrm{TiO}_{2}$ (anatase) and methylene blue were used as a model of the UVA-induced reaction. The sample solution containing methylene blue and $\mathrm{TiO}_{2}$ dispersion in sodium phosphate buffer ( $\mathrm{pH}$ 7.6) with or without metal nanoparticle was irradiated with a UVA lamp (365 nm, 1 
$\mathrm{mW} \mathrm{cm}^{-2}$ ). The decomposition of methylene blue was evaluated by absorption measurement at $659 \mathrm{~nm} . \mathrm{TiO}_{2}$ is a well-known photocatalyst (Fujishima et al., 2000, 2008). When exposing to UVA light, the reduction-oxidation activity of $\mathrm{TiO}_{2}$ has a significant biological impact, as is exemplified by its bactericidal activity. Photo-irradiated $\mathrm{TiO}_{2}$ effectively decomposed methylene blue (Figure 17). Various reactive oxygen species contribute to the photocatalytic reaction of $\mathrm{TiO}_{2}$. Especially, hydrogen peroxide is long-lived reactive oxygen species and plays an important role in oxidative biomolecules damage. Molecular oxygen is reduced by photoexcited materials, leading to the formation of superoxide. Formed superoxide is rapidly dismutated into hydrogen peroxide. Although hydrogen peroxide itself is not a strong reactive species, it can generate highly reactive hydroxyl radicals through a Fenton reaction or a Haber-Weiss reaction. Furthermore, hydrogen peroxide can penetrate a cytoplasm membrane and be incorporated into the cell nucleous. Therefore, hydrogen peroxide is considered to be one of the most important reactive oxygen species participating in UVA carcinogenesis and phototoxicity. Since other reactive oxygen species, such as directly produced hydroxyl radicals (Hirakawa et al., 2004) and singlet oxygen (Hirakawa \& Hirano, 2006), rapidly quenched in aqueous solution, hydrogen peroxide should be key reactive species in this experiment. The $\mathrm{TiO}_{2}$ and methylene blue could be used as a simple model of UVA-induced oxidation.

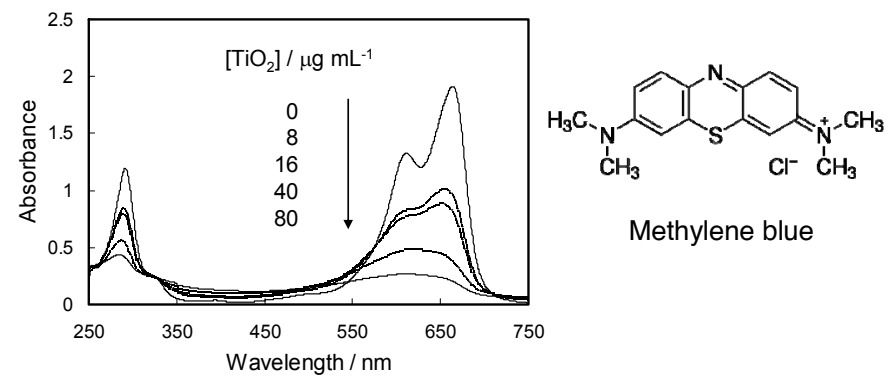

Fig. 17. UV-Vis absorption spectra of methylene blue photocatalyzed by $\mathrm{TiO}_{2}$. The sample solution containing $10 \mu \mathrm{M}$ methylene blue and indicated concentration of $\mathrm{TiO}_{2}$ in $10 \mathrm{mM}$ sodium phosphate buffer ( $\mathrm{pH} 7.6)$ was irradiated $\left(\mathrm{Ex}=365 \mathrm{~nm}, 1 \mathrm{~mW} \mathrm{~cm}^{-2}\right)$ for $30 \mathrm{~min}$.

\subsubsection{Preventive action of metal nanoparticles on ultraviolet radiation induced biomolecules damage}

Poly(N-vinyl-2-pyrrolidone)-protected metal nanoparticles, in particular, the $\mathrm{Pt}$ nanoparticle, inhibited the methylene blue decomposition photocatalyzed by $\mathrm{TiO}_{2}$ (Figure 18). Poly( $N$-vinyl-2-pyrrolidone) itself did not inhibit the methylene blue decomposition. This inhibitory effect can be explained by the catalytic decomposition of $\mathrm{H}_{2} \mathrm{O}_{2}$ generated through $\mathrm{TiO}_{2}$ photocatalysis. These nanoparticles decomposed $\mathrm{H}_{2} \mathrm{O}_{2}$ into $\mathrm{H}_{2} \mathrm{O}$ and $\mathrm{O}_{2}$ similar to catalase. In the case of $\mathrm{H}_{2} \mathrm{O}_{2}$ decomposition, the $\mathrm{Pt}$ nanoparticle showed the highest catalytic activity per unit atom. The activity of a $1 \mu \mathrm{g} \mathrm{Pt}$ nanoparticle was comparable to that of 5 units of catalase. One unit of catalase can remove $1.0 \mu \mathrm{mol} \mathrm{H}_{2} \mathrm{O}_{2}$ per $1 \mathrm{~min}$ in water $\left(\mathrm{pH} 7.0,25^{\circ} \mathrm{C}\right)$. Unexpectedly, the bimetallization with $\mathrm{Ag}$ did not show improvement effect and rather decreased the inhibitory effect of Pt nanoparticle on the decomposition of methylene blue. 
The UV-Vis absorption spectra of these metal nanoparticles were hardly changed by the photocatalytic reaction, suggesting that the noble metal nanoparticles are stable for reactive oxygen species and UVA irradiation. Organic antioxidant undergoes oxidation in the removal process of reactive oxygen species, leading to the formation of various oxidized products and may produce secondary reactive oxygen species. In the case of noble metal catalyst, these effects can be negligible.

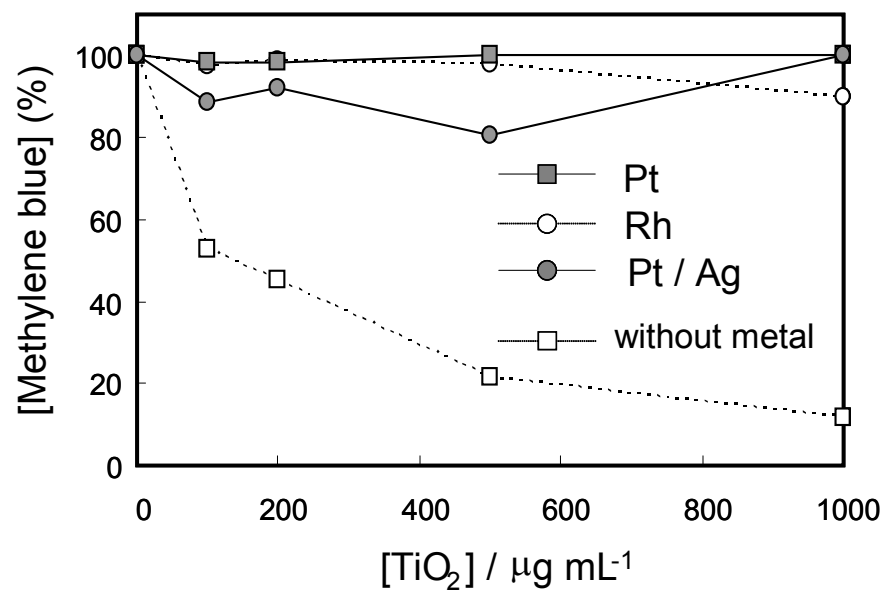

Fig. 18. Inhibitory effect of metal nanoparticles on methylene blue decomposition photocatalyzed by $\mathrm{TiO}_{2}$. The sample solution containing $20 \mu \mathrm{g} \mathrm{mL}^{-1}$ metal nanoparticle, $\mathrm{TiO}_{2}$, and $10 \mu \mathrm{M}$ methylene blue in $10 \mathrm{mM}$ sodium phosphate buffer (pH 7.6) was irradiated $\left(\mathrm{Ex}=365 \mathrm{~nm}, 1 \mathrm{~mW} \mathrm{~cm}^{-2}\right)$ for $30 \mathrm{~min}$.

\subsection{Summary of the ultraviolet protection by metal nanoparticles}

$\mathrm{Pt}, \mathrm{Rh}$, and $\mathrm{Pt} / \mathrm{Ag}$ nanoparticles effectively inhibited the methylene blue decomposition photocatalyzed by $\mathrm{TiO}_{2}$. $\mathrm{TiO}_{2}$ photocatalytic system was used as a UVA-induced reactive oxygen species generation. The most important reactive oxygen species in this photocatalytic reaction is $\mathrm{H}_{2} \mathrm{O}_{2}$, because of its long lifetime in aqueous solution. This inhibitory effect of metal nanoparticle can be explained by the removal of $\mathrm{H}_{2} \mathrm{O}_{2}$. Unexpectedly, the activity of Pt nanoparticle was not improved by the bimetallization with Ag. Platinum is a very stable metal against various chemical compounds and is used as food additive. A poly(N-vinyl-2-pyrrolidone)-protected $\mathrm{Pt}$ nanoparticle may be used as a novel preventive agent for UVA-induced biomolecules damage through reactive oxygen species generation.

\section{Conclusion}

Physical mixture of $\mathrm{Ag}$ and other metal nanoparticles, such as $\mathrm{Pt}, \mathrm{Rh}$, and $\mathrm{Pd}$, spontaneously forms the bimetallic nanoparticles with Ag-core structure in aqueous solution. These monometallic nanoparticles can be easily prepared from an alcohol reduction of the corresponding metal ions in the presence of water-soluble polymer such 
as poly( $N$-vinyl-2-pyrrolidone), a protective colloid. Aqueous sol of Ag nanoparticles exhibits the surface plasmon absorption around $400 \mathrm{~nm}$. The surface plasmon absorption was diminished through interaction with other metal nanoparticle in the physical mixture of these nanoparticles. This phenomenon was explained by that the Ag nanoparticle was coated by other metal. The transmission electron micrograph and X-ray diffraction measurement confirmed the formation of the Ag-core bimetallic nanoparticles. This reaction can be used to construct the core-shell structured novel bimetallic nanoparticles. The formed nanoparticles act superior character for certain catalytic reactions. The catalytic activity of the silver/rhodium bimetallic nanoparticles for visible-light-induced hydrogen generation in an aqueous solution was examined. This system composed of an electron source, a photosensitizer, an electron relay, and metal nanoparticle catalyst. The activity is clearly higher than the corresponding monometallic nanoparticles, suggesting that the silver-core enhances the catalytic activity of the surface rhodium. On the other hand, the catalytic activity of the decomposition of hydrogen peroxide was decreased by this bimetallization. Platinum nanoparticle effectively catalyzes hydrogen peroxide decomposition. The Ag-core/platinum shell bimetallic nanoparticle, which was prepared by the physical mixing of $\mathrm{Ag}$ and $\mathrm{Pt}$ nanoparticles, demonstrated lower activity of the decomposition of hydrogen peroxide than the monometallic Pt nanoparticle. Metal nanoparticles can be applied to various catalytic reactions. The bimetallic and trimetallic nanoparticles demonstrate superior activity in the certain reaction. The self-assembly formation of Ag-cored nanoparticle may be convenient method to prepare novel metal nanoparticle catalyst.

\section{Acknowledgments}

The author wish to thank Professor Naoki Toshima (Tokyo University of Science, Yamaguchi) for his helpful discussion and Professor Kenji Murakami (Research Institute of Electronics, Shizuoka University) for his helpful advice on TEM measurement. These works were supported by a Grant-in-Aid for Scientific Research from the Ministry of Education, Culture, Sports, Science and Technology (MEXT) of the Japanese Government.

\section{References}

Akinaga, H. (2002). Metal-nanocluster Equipped GaAs Surfaces Designed for High-sensitive Magnetic Field Sensors. Surface Science, Vol.514, No.1-3, (August 2002), pp.145-150, ISSN 0039-6028

Baumgartner, H. J.; Hood, G. C.; Monger, J. M.; Roberts, R. M. \& Sanborn, C. E. (1963). Decomposition of Concentrated Hydrogen Peroxide on Silver I. Low Temperature Reaction and Kinetics. Journal of Catalysis, Vol.2, No.5, (October 1963), pp.405-414, ISSN 0021-9517

Bianchi, G.; Mazza, F. \& Mussini, T. (1962). Catalytic Decomposition of Acid Hydrogen Peroxide Solutions on Platinum, Iridium, Palladium and Gold Surfaces. Electrochimica Acta, Vol.7, No.4, (July-August 1962), pp.457-473, ISSN 0013-4686 
Bonilla, R. J.; James, B. R. \& Jessop, P. G. (2000). Colloid-catalyzed Arene Hydrogenation in Aqueous/Supercritical Fluid Biphasic Media. Chemical Communications, No.11, (May 2000), pp.941-942, ISSN 1359-7345

Bönnemann, H. \& Richards, R. M. (2001). Nanoscopic Metal Particles-Synthetic Methods and Potential Applications. Europian Journal of Inorganic Chemistry, Vol.2001, No.10, (October 2001), pp.2455-2480, ISSN 1099-0682

Bradley, J. S. (1994). In: Clusters and Colloids: From Theory and Applications, G. Schmid (Ed), 456-544, VCH, ISBN 3527290435, Weinheim

Cadet, J.; Douki, T.; Gasparutto, D. And Ravanat, J. L. (2003). Oxidative Damage to DNA: Formation, Measurement and Biochemical Features. Mutation Research, Vol.531, No.1-2, (October 2003), pp.5-23, ISSN 0027-5107

Drechsel, D. A. \& Patel, M. (2008). Mechanisms of Environmental Neurotoxicant-induced Oxidative Stress. Free Radical Biology and Medicine, Vol.44, No.11, (June 2008), pp.1873-1886, ISSN 0891-5849

Eley, D. D. \& Macmahon D. M., (1972). The Decomposition of Hydrogen Peroxide Catalyzed by Palladium-gold Alloy Wires. Journal of Colloid and Interface Science, Vol.38, No.2, (February 1972), pp.502-510. ISSN: 0021-9797

Fujishima, A.; Rao, T. N. \& Tryk, D. A. (2000). Titanium Dioxide Photocatalysis. Journal of Photochemistry and Photobiology C: Photochemistry Reviews, Vol.1, No.1, (June 2000), pp.1-21, ISSN 1389-5567

Fujishima, A.; Zhang, X. \& Tryk, D. A. $\mathrm{TiO}_{2}$. (2008). Photocatalysis and Related Surface Phenomena. Surface Science Reports, Vol.63, No.12, (December 2008), pp.515-582, ISSN 0167-5729

Fukumi, K.; Chayahara, A,; Kadono, K.; Sakaguchi, T.; Horino, Y.; Miya, M.; Fujii, K,.; Hayakawa, J. \& Satou, M. (1994). Gold Nanoparticles Ion Implanted in Glass with Enhanced Nonlinear Optical Properties, Journal of Applied Physics; Vol.75, No.6, (March 1994), pp.3075-3080, ISSN 0021-8979

Goszner, K.; Körner, D. \& Hite, R. (1972). On the Catalytic Activity of Silver: I. Activity, Poisoning, and Regeneration during the Decomposition of Hydrogen Peroxide. Journal of Catalysis, Vol.25, No.2, (May 1973), pp.245-253, ISSN 0021-9517

Goszner, K. \& Bischof, H. (1974). The Decomposition of Hydrogen Peroxide on Silver-gold Alloys. Journal of Catalysis, Vol.32, No.2, (February 1974), pp.175-1820, ISSN 00219517

Harriman, A. (1990). Bimetallic Pt-Au Colloids as Catalysts for Photochemical Dehydrogenation. Journal of the Chemical Society, Chemical Communications, No.1, (January 1990), pp.24-26, ISSN 0022-4936

Henglein, A. (1979). Catalysis of the Reduction of Thallium(1+) and of Dichloromethane by Colloidal Silver in Aqueous Solution. The Journal of Physical Chemistry, Vol.83, No.22, (November 1979), pp.2858-2862, ISSN 0022-3654

Henglein, A.; Holzwarth, A. \& Malvaney, P. (1992). Fermi Level Equilibration between Colloidal lead and Silver Particles in Aqueous Solution. The Journal of Physical Chemistry, Vol.96, No.22, (October 1992), pp.8700-8702, ISSN 0022-3654 
Hirai, H.; Nakao, Y. \& Toshima, N. (1979). Preparation of Colloidal Transition Metals in Polymers by Reduction with Alcohols or Ethers. Journal of Macromolecular Science: Part A-Chemistry, Vol.13, No.6, (1979), pp.727-750, ISSN 0022-233X

Yamaji, Y.; Hirakawa, K.; Yonezawa, T. \& Toshima, N. (1995). Visible-light-induced Reduction of Carbon Dioxide Using Platinum Colloidal Catalyst. Proceedings of Annual Meeting on Photochemistry 1995, pp.B1080, Fukuoka, Japan, October 6-9, 1995

Hirakawa, K.; Oikawa, S.; Hiraku, Y.; Hirosawa, I. \& Kawanishi, S. (2002). Catechol and Hydroquinone Have Different Redox Properties Responsible for Their Differential DNA-damaging Ability. Chemical Research in Toxicology, Vol.15, No.1, (January 2002), pp.76-82, ISSN 0893-228X

Hirakawa, K. \& Toshima, N. (2003). Ag/Rh Bimetallic Nanoparticles Formed by Selfassembly from $\mathrm{Ag}$ and $\mathrm{Rh}$ Monometallic Nanoparticles in Solution. Chemistry Letters, Vol.32, No.1, (January 2003), pp.78-79, ISSN 0366-7022

Hirakawa, K.; Mori, M.; Yoshida, M.; Oikawa, S. \& Kawanishi, S. (2004). Photo-irradiated Titanium Dioxide Catalyzes Site Specific DNA Damage via Generation of Hydrogen Peroxide, Free Radical Research, Vol.38, No.5, (May 2004), pp.439-447, ISSN 1071-5762

Hirakawa, K. \& Hirano, T. (2006). Singlet Oxygen Generation Photocatalyzed by $\mathrm{TiO}_{2}$ Particles and Its Contribution to Biomolecule Damage. Chemistry Letters, Vo.35, No.8, (August 2006), pp.832-833, ISSN 0366-7022

Hirakawa, K. (2006). Fluorometry of Hydrogen Peroxide Using Oxidative Decomposition of Folic Acid. Analytical and Bioanalytical Chemistry, Vol.386, No.2, (September 2006), pp.244-248, ISSN 1618-2642

Hirakawa, K. (2007). Preparation of Novel Metal Nanoparticles and Their Catalytic and Photocatalytic Properties. Reports of Researches Assisted by the Asahi Glass Foundation (2007), No.53, (October 2007) pp.1-10, ISSN 0919-9179

Hirakawa, K.; Shiota, K. \& Sano, S. (2008). Preventive Action of Metal Nanoparticles on UVA-sensitized Oxidation through Hydrogen Peroxide Formation. Photomedicine and Photobiology, Vol.30, (July 2008), pp.27-28, ISSN 0912-232X

Hirakawa, K. \& Sano, S. (2009). Platinum Nanoparticle Catalyst Scavenges Hydrogen Peroxide Generated from Hydroquinone. Bulletin of the Chemical Society of Japan, Vol.82, No.10, (October 2009), pp.1299-1303, ISSN 0009-2673

Hirakawa, K. (2009). Evaluation and Chemoprevention of Phototoxic Effect by the Novel Materials. Photomedicine and Photobiology, Vo.31, (July 2009), pp.33-34, ISSN 0912$232 X$

Hiraku, Y.; Ito, K.; Hirakawa, K. \& Kawanishi, S. (2007). Photosensitized DNA Damage and Its Protection via a Novel Mechanism. Photochemistry and Photobiology, Vo.83, No.1, (January 2007), pp.205-212, ISSN 1751-1097

Ishitani, O.; Inoue, C.; Suzuki, Y. \& Ibusuki, T. (1993). Photocatalytic Reduction of Carbon Dioxide to Methane and Acetic Acid by an Aqueous Suspension of MetalDeposited $\mathrm{TiO}_{2}$. Journal of Photochemistry and Photobiology A: Chemistry, Vol.72, No.3, (June 1993), pp.269-271, ISSN 1010-6030 
Kajita, M.; Hikosaka, K.; Iitsuka, M.; Kanayama, A.; Toshima, N. \& Miyamoto, Y. (2007). Platinum Nanoparticle Is a Useful Scavenger of Superoxide Anion and Hydrogen Peroxide. Free Radical Research, Vol.41, No.6, (January 2007), pp.615-626, ISSN 10715762

Kawanishi, S.; Hiraku, Y. \& Oikawa, S. (2001). Mechanism of Guanine-specific DNA Damage by Oxidative Stress and Its Role in Carcinogenesis and Aging. Mutation Research, Vol.488, No.1, (March 2001), pp.65-76, ISSN 0027-5107

Keating, K. B.; Rozner, A. G. \& Youngblood, J. L. (1965). The Effect of Deformation on Catalytic Activity of Platinum in the Decomposition of Hydrogen Peroxide. Journal of Catalysis, Vol.4, No.5, (October 1965), pp.608-619, ISSN 0021-9517

Kiely, C. J.; Fink, J.; Brust, M.; Bethell, D. \& Schiffrin, D. J. (1998). Spontaneous Ordering of Bimodal Ensembles of Nanoscopic Gold Clusters. Nature, Vol.396, pp.444-446, (December 1998), ISSN 0028-0836

Lee, A. F.; Baddeley, C. J.; Hardacre, C.; Ormerod, R. M.; Lambert, R. M.; Schmid, G. \& West, H. (1995). Structural and Catalytic Properties of Novel Au/Pd Bimetallic Colloid Particles: EXAFS, XRD, and Acetylene Coupling. The Journal of Physical Chemistry, Vol.99, No.16, (Aprile 1995), pp.6096-6102, ISSN 0022-3654

Link, S:; Wang, Z. L. \& El-Sayed, M. A. (1999). Alloy Formation of Gold-Silver Nanoparticles and the Dependence of the Plasmon Absorption on Their Composition. The Journal of Physical Chemistry B, Vol.103, No.18, (Aprile 1999), pp.3529-3533, ISSN 1520-6106

Lu, P.; Dong, J. \& Toshima, N. (1999). Surface-Enhanced Raman Scattering of a Cu/Pd Alloy Colloid Protected by Poly(N-vinyl-2-pyrrolidone). Langmuir, Vol.15, No.23, (September 1999), pp.7980-7992, ISSN 0743-7463

Matsushita, T.; Shiraishi, Y.; Horiuchi, S. \& Toshima, N. (2007). Synthesis and Catalysis of Polymer-Protected $\mathrm{Pd} / \mathrm{Ag} / \mathrm{Rh}$ Trimetallic Nanoparticles with a Core-Shell Structure. Bulletin of the Chemical Society of Japan, Vol.80, No.6, (June 2007), 12171225, ISSN 0009-2673

McKee, D. W. (1969). Catalytic Decomposition of Hydrogen Peroxide by Metals and Alloys of the Platinum Group. Journal of Catalysis, Vol.14, No.4, (August 1969), pp.355-364, ISSN 0021-9517

Murata, M. \& Kawanishi, S. (2000). Oxidative DNA Damage by Vitamin A and Its Derivative via Superoxide Generation. The Journal of Biological Chemistry, Vol.275, No.3, (January 2000), pp.2003-2008, ISSN 0021-9258

Nitta, Y.; Kamiya, K.; Tanimoto, M.; Sadamoto, S.; Niwa, O. \& Yokoro, K. (1991). Induction of Transplantable Tumors by Repeated Subcutaneous Injections of Natural and Synthetic Vitamin E in Mice and Rats. Japanese Journal of Cancer Research, Vol.82, No.5, (May 1991), pp.511-517, ISSN 0910-5050

Oikawa, S.; Furukawa, A.; Asada, H.; Hirakawa, K. \& Kawanishi, S. (2003). Catechins Induce Oxidative Damage to Cellular and Isolated DNA through the Generation of Reactive Oxygen Species. Free Radical Research, Vol. 37, No.8, pp.881-890, (August 2003), ISSN 1071-5762

Omenn, G. S.; Goodman, G. E.; Thornquist, M. D.; Balmes, J.; Cullen, M. R.; Glass, A.; Keogh, J. P.; Meyskens Jr, F. L.; Valanis, B.; Williams Jr, J. H.; Barnhart, S.; 
Cherniack, M. G.; Brodkin, C. A. \& Hammar, S. (1996). Risk Factors for Lung Cancer and for Intervention Effects in CARET, the Beta-Carotene and Retinol Efficacy Trial. Journal of the National Cancer Institute, Vol.88, No.21, (Novenber 1996), pp.1550-1559, ISSN 0027-8874

Peiner, E. \& Kopitzki, K. (1988). Metastable Phases Formed by Ion Beam Mixing of Binary Metal Systems with Positive Heats of Hormation. Nuclear Instruments and Methods in Physics Research Section B: Beam Interactions with Materials and Atoms, Vol.134, No.2, (August 1988), pp.173-180, ISSN 0168-583X

Pileni, M. P. (1998). Preparation, Characterization and Application, In: Nanoparticles and Nanostructured Films:, J. H. Fendler (Ed.), 71-100, Wiely-VCH, ISBN 3527294430, Weinheim

Shipway, A. N.; Katz, E. \& Willner, I. (2000). Nanoparticle Arrays on Surfaces for Electronic, Optical, and Sensor Applications. ChemPhysChem, Vol.1, No.1, (August 2000), pp.18-52, ISSN 1439-7641

Shiraishi, Y. \& Toshima, N. (1999). Colloidal Silver Catalysts for Oxidation of Ethylene. Journal of Molecular Catalysis A: Chemical, Vol.141, No.1-3, (May 1999), pp.187-192, ISSN 1381-1169

Siepen, K.; Bönnemann, H.; Brijoux, W.; Rothe, J. \& Hormes, J. (2000). EXAFS/XANES, Chemisorption and IR Investigations of Colloidal Pt/Rh Bimetallic Catalysts. Applied Organometallic Chemistry, Vol.14, No.10, (October 2000), pp.549-556, ISSN 1099-0739

T. J. Slaga, (1995). Inhibition of Skin Tumor Initiation, Promotion, and Progression by Antioxidants and Related Compounds. Critical Reviews in Food Science and Nutrition, Vol.35, No.1-2, (January 1995), pp.51-57, ISSN 1040-8398

Sohmiya, M.; Tanaka, M.; Okamoto, K.; Fujisawa, A. \& Yamamoto, Y. (2004). Synergistic Inhibition of Lipid Peroxidation by Vitamin E and a Dopamine agonist, Cabergoline. Neurological Research, Vol.26, No.4, (June 2004), pp.418-421, ISSN 17431328

Solovieva, M. E.; Soloviev, V. V. \& Akatov, V. S. (2007). Vitamin B12b Increases the Cytotoxicity of Short-time Exposure to Ascorbic acid, Inducing Oxidative Burst and Iron-Dependent DNA Damage. European Journal of Pharmacology, Vol.566, No.1-3, (July 2007), pp.206-214, ISSN 0014-2999

Solovieva, M. E.; Soloviev, V. V.; Kudryavtsev, A. A.; Trizna, Y. A. \& Akatov, V. S. (2008). Vitamin B12b Enhances the Cytotoxicity of Dithiothreitol. Free Radical Biology and Medicine, Vol.44, No.10, (May 2008), pp.1846-1856, ISSN 0891-5849

Sun, S.; Murray, C. B.; Weller, D.; Folks, L. \& Moser, A. (1999). Monodisperse FePt Nanoparticles and Ferromagnetic FePt Nanocrystal Superlattices. Science, Vol.287, No. 5460, (March 1999), pp.1989-1992, ISSN 0036-8075

Teranishi ,T. \& Miyake, M. (1999). Novel Synthesis of Monodispersed Pd/Ni Nanoparticles. Chemistry of Materials, Vol.11, No.12, (November 1999), pp.3414-3416, ISSN 08974756

Toshima, N. \& Wang, Y. (1994). Polymer-protected Cu/Pd Bimetallic Clusters. Advanced Materials, Vol.6, No.3, (March 1994), pp.245-247, ISSN 1521-4095 
Toshima, N.; Yamaji, Y.; Teranishi, T. \& Yonezawa, T. (1995). Photosensitized Reduction of Carbon Dioxide in Solution Using Noble Metal Clusters for Electron Transfer. Zeitschrift für Naturforschung A, Vol.50a, pp.283-291, ISSN 0932-0784

Toshima, N. \& Hirakawa, K. (1997). Polymer-protected Pt/Ru Bimetallic Cluster Catalysts for Visible-light-induced Hydrogen Generation from Water and Electron Transfer Dynamics. Applied Surface Science, Vol.121/122, (November 1997), pp.534-537, ISSN 0169-4332

Toshima, N. \& Hirakawa, K. (1999). Polymer-Protected Bimetallic Nanocluster Catalysts Having Core/Shell Structure for Accelerated Electron Transfer in Visible-LightInduced Hydrogen Generation. Polymer Journal, Vol.31, No.11, (November 1999), pp.1127-1132, ISSN 0032-3896

Toshima, N.; Shiraishi, Y.; Matsushita, T.; Mukai, H. \& Hirakawa, K. (2002). Selforganization of Metal Nanoparticles and Its Application to Synthesis of $\mathrm{Pd} / \mathrm{Ag} / \mathrm{Rh}$ Trimetallic Nanoparticle Catalysts with Triple Core/Shell Structures. International Journal of Nanoscience, Vol.1, No.5-6, (December 2002), pp.397-401, ISSN 0219-581X

Toshima, N.; Kanemaru, M.; Shiraishi, Y. \& Koga, Y. (2005). Spontaneous Formation of Core/Shell Bimetallic Nanoparticles: A Calorimetric Study. The Journal of Physical Chemistry B, Vol.109, No.24, (August 2005), pp.16326-16331, ISSN 1520-6106

Toshima, N.; Ito, R.; Matsushita, T. \& Shiraishi, Y. (2007), Trimetallic Nanoparticles Having a Au-core Structure. Catalysis Today, Vol.122, No.3-4, (Aprile 2007), pp.239-244, ISSN 0920-5861

Toshima, N. \& Zhang, H. (2011). Preparation of Novel Au/Pt/Ag Trimetallic Nanoparticles and Their High Catalytic Activity for Aerobic Glucose Oxidation. Applied Catalysis A: General, Vol.400, No.1-2, (June 2011), pp.9-13, ISSN 0926-860X

Weyant, M. J.; Carothers, A. M.; Dannenberg, A. J. \& Bertagnolli, M. M. (2001). (+)-Catechin Inhibits Intestinal Tumor Formation and Suppresses Focal Adhesion Kinase Activation in the Min/+ Mouse. Cancer Research, Vol.61, No.1, (January 2001), pp.118-125, ISSN 0008-5472

Widegren, J. A. \& Finke, R. G. (2003). A Review of Soluble Transition-metal Nanoclusters as Arene Hydrogenation Catalysts. Journal of Molecular Catalysis A: Chemical, Vol.191, No.2, (January 2003), pp.187-207, ISSN 1381-1169

Willner, I.; Maiden, R.; Mandler, D.; Dürr, H.; Dörr, G. \& Zengerle, K. (1987). Photosensitized Reduction of Carbon Dioxide to Methane and Hydrogen Evolution in the Presence of Ruthenium and Osmium Colloids: Strategies to Design Selectivity of Products Distribution. Journal of the American Chemical Society, Vol.109, No.20, (September 1987), pp.6080-6086, ISSN 0002-7863

Yamashita, N.; Murata, M.; Inoue, S.; Burkitt, M. J.; Milne, L. \& Kawanishi, S. (1998). Alphatocopherol Induces Oxidative Damage to DNA in the Presence of Copper(II) Ions. Chemical Research in Toxicology, Vol.11, No.8, (August 1998), pp.855-862, ISSN 0893$228 \mathrm{X}$

Yonezawa, T. \& Toshima, N. (1993). Polymer- and Micelle-protected Gold/Platinum Bimetallic Systems. Preparation, Application to Catalysis for Visible-lightinduced Hydrogen Evolution, and Analysis of Formation Process with Optical 
Methods. Journal of Molecular Catalysis, Vol.83, No.1-2, (July 1993), pp.167-181, ISSN 1381-1169

Yonezawa, T. \& Toshima, N. (1995). Mechanistic Consideration of Formation of Polymerprotected Nanoscopic Bimetallic Clusters. Journal of the Chemical Society, Faraday Transactions, Vol.91, No.22, (November 1995), pp.4111-4119, ISSN 0956-5000 


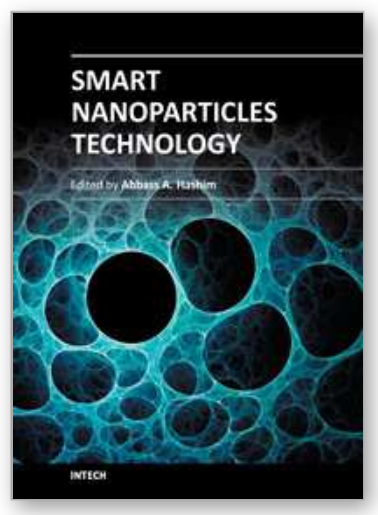

\author{
Smart Nanoparticles Technology \\ Edited by Dr. Abbass Hashim
}

ISBN 978-953-51-0500-8

Hard cover, 576 pages

Publisher InTech

Published online 18, April, 2012

Published in print edition April, 2012

In the last few years, Nanoparticles and their applications dramatically diverted science in the direction of brand new philosophy. The properties of many conventional materials changed when formed from nanoparticles. Nanoparticles have a greater surface area per weight than larger particles which causes them to be more reactive and effective than other molecules. In this book, we (InTech publisher, editor and authors) have invested a lot of effort to include 25 most advanced technology chapters. The book is organised into three well-heeled parts. We would like to invite all Nanotechnology scientists to read and share the knowledge and contents of this book.

\title{
How to reference
}

In order to correctly reference this scholarly work, feel free to copy and paste the following:

Kazutaka Hirakawa (2012). Self-Organization of Silver-Core Bimetallic Nanoparticles and Their Application for Catalytic Reaction, Smart Nanoparticles Technology, Dr. Abbass Hashim (Ed.), ISBN: 978-953-51-0500-8, InTech, Available from: http://www.intechopen.com/books/smart-nanoparticles-technology/self-organization-ofsilver-core-bimetallic-nanoparticles-and-their-application-for-catalytic-reacti

\section{INTECH}

open science | open minds

\section{InTech Europe}

University Campus STeP Ri

Slavka Krautzeka 83/A

51000 Rijeka, Croatia

Phone: +385 (51) 770447

Fax: +385 (51) 686166

www.intechopen.com

\section{InTech China}

Unit 405, Office Block, Hotel Equatorial Shanghai

No.65, Yan An Road (West), Shanghai, 200040, China 中国上海市延安西路65号上海国际贵都大饭店办公楼 405 单元

Phone: +86-21-62489820

Fax: $+86-21-62489821$ 
(C) 2012 The Author(s). Licensee IntechOpen. This is an open access article distributed under the terms of the Creative Commons Attribution 3.0 License, which permits unrestricted use, distribution, and reproduction in any medium, provided the original work is properly cited. 